Ssciendo Studia Anglica Posnaniensia 56s1 (2021): 511-550

doi: 10.2478/stap-2021-0007

\title{
DISSECTING THE WORD: THE USE OF THE LEXEME SHIT IN SELECTED PERFORMANCES OF COMEDIAN DAVE CHAPPELLE'S STAND-UP ROUTINE
}

\author{
RADOSŁAW DYLEWSKI ${ }^{1}$
}

\begin{abstract}
The paper explores the use of the lexeme shit in the corpus of Dave Chappelle's stand-up specials released between 2000 and 2019. It consists of two parts: theoretical and analytical. The first one presents theoretical and pragmatic considerations connected with stand-up routines, touches upon slang semantics, and depicts the links between Dave Chappelle's stage persona and the hip hop community. Lastly, it presents the reader with the past and present-day status of the lexeme at issue. In the analytical section of the paper the use of shit in the aforesaid corpus is scrutinized from the semantic angle. The discussion is supplemented with the results culled from the corpus of rap lyrics compiled at the Faculty of English at Adam Mickiewicz University in Poznan. The paper argues that (i) shit has lost its taboo status and is mainly used in both corpora as a less formal equivalent of stuff, anything and something and (ii) Chappelle's stage use of shit, even though present in a different context and serving context-specific purposes, corresponds to the use of African American rappers in their song lyrics (assuming that rap lyrics depict African American English, this conclusion can be extended to the sociolect of African Americans).
\end{abstract}

Keywords: Vulgarisms; profanity; shit; semantic bleaching; Dave Chappelle's comedies.

\section{Introduction}

Dave Chappelle, one of the most popular African American stand-up comedians in the United States, ${ }^{2}$ enjoys immense popularity thanks to his critically acclaimed satirical sketch series Chappelle's Show, running between 2003 and

Faculty of English at Adam Mickiewicz University in Poznań. Grunwaldzka 6, 60-780 Poznań, Poland.dradek@amu.edu.pl

2 As well as being a successful stand-up comedian, Chappelle is also an actor appearing in a number of films and the $\mathrm{ABC}$ comedy "Buddies", writer, and producer. He is also a recipient of both an Emmy and a Grammy. 
2006. For a number of reasons, he took a career-break for some years. This break, however, was interspersed with occasional stand-up performances and TV appearances. ${ }^{3}$ Chappelle's career was revived when he signed a multimilliondollar deal with the American media-service provider Netflix, where one may watch the stand-up performances studied in this analysis.

The language of Chappelle's stage persona, unfettered by political correctness, ${ }^{4}$ poking fun at everybody, and breaching social taboo, is replete with words and phrases, on the one hand, commonly considered taboo. ${ }^{5}$ On the other, some are typical of African American English, if not specifically of the rap ${ }^{6}$ language style. ${ }^{7}$ Chappelle is a keen fan of African American rap ${ }^{8}$ and frequently pays homage to it in his acts, so the linguistic link with the language of rap cannot be overlooked.

The aim of this paper is to explore Chappelle's usage of just one lexeme, shit, in a selection of his stand-up performances. It has been assumed that by the use of words and expressions characterized by their extravagance and taboo edge not only does Chappelle want to achieve playfulness and humor, but also to release the audience "from the monotony of neutral style", to add color to his monologs, and to challenge the audience (Mattiello 2008: 60).

To claim that the use of shit is no more than using a simple taboo term or just a "dirty word" is, however, an oversimplification: ${ }^{9}$ it is hoped that the analysis that

https://en.wikipedia.org/wiki/Dave_Chappelle, date of access 20/01/2020.

Bucaria (2017) claims that in recent years the intensity and popularity of such jokes has increased, especially in Anglo-American popular culture. She notes that, while until recently obscene and politically incorrect humor was characteristic of only certain genres, such as the focal point of this paper, i.e., stand-up comedy, today it has spread into mainstream films and TV shows, posing a challenge to audiovisual translators (Bucaria 2017: 438).

5 "Taboo refers to a proscription of behaviour for a specifiable community of one or more persons at a specifiable time in specifiable contexts. For behaviour to be proscribed it must be perceived as in some way harmful to an individual or their community but the degree of harm can fall anywhere on a scale from a breach of etiquette to out-and-out fatality. All tabooed behaviours are deprecated and they lead to social if not legal sanction" (Allan 2018: 1).

6 In this paper we shall adhere to the traditional division between rap (music) and hip-hop (the whole culture, a part of which alongside, for example, breakdancing and graffiti is rap).

7 For some scholars, rap lyrics are the ones depicting African American English. Tottie (2002: 219), for example, says, "Most people have probably heard specimens of AAVE even if they have never been to the United States, either in movies or in rap lyrics". We, however, take our lead from Cutler (2007: 521) who says the following: "Researchers often use the term 'language' in a loose sense to describe the linguistic variety associated with hip-hop and its relationship to AAE, but the degree to which the linguistic features of HHL overlap with those of AAE actually makes it difficult to argue that it constitutes a language unto itself. Perhaps 'language style' is a more appropriate designation, particularly in view of the fact that HHL is highly variable and transitory, as Alim (2004...) and Morgan (1993) have pointed out".

8 This also includes the African American hip-hop culture in its entirety.

9 Taboo status may also vary over time and we would like to show that shit has lost its status and seems to be a marker of colloquial style and in the case of stand-up comedy it adds spice 
follows will demonstrate that its intensive usage in colloquial English in the US and a subsequent semantic bleaching mean that this lexeme, as employed by Dave Chappelle in his routines, is less profane and less vulgar than one might assume. In the majority of contexts, in fact, shit in conjunction with both demonstrative adjectives and the is used as a simple anaphoric construction..$^{10}$ Chappelle's use also seems to parallel that of African American rappers ${ }^{11}$ and it additionally serves to underline Chappelle's in-group identity and membership, and facilitates solidarity with the African American community. His use of the lexeme will therefore be compared to the results retrieved from the corpus of rap lyrics compiled at the Faculty of English at Adam Mickiewicz University in Poznań.

Here we shall concur with Jay (1992: 9) ${ }^{12}$ who writes that "[i]n fact one has to look at the entire sentence and speech context to see how the word was used. ... Shit could be used as scatology, insult, or epithet. Jesus Christ could be an epithet or profanity. One does not know for sure by looking at the word alone. One must consider how the speaker used it". Beers Fägersten is also undoubtedly correct in her claim that "[t]he traditional word-list method can neither account for the variations of swearword usage, such as literal or metaphorical usage, nor for the effects of variations in context, such as setting, topic and co-participants" (2012: 94). We have thus looked at a wider context to determine whether shit has been used more frequently in its literal (or denotative) interpretation, or in its connotative or emotional overtones. By means of the LancsBox corpus toolbox we also retrieved automatically the most frequent collocates of the word from two corpora: one comprising Dave Chappelle's acts and the other rap lyrics. ${ }^{13}$

The choice of the study material was governed by both scholarly and practical issues. In the first place, stand-up comedy has thus far been analyzed from a variety of angles (e.g., Prussing-Hollowell 2008; Gillota 2015) amongst which a linguistic analysis (Schwarz 2010), not to mention semantic analysis (e.g., Seizer 2011), is by far underrepresented. This paper thus seeks to fill this void in scholarly endeavors, focusing on stand-up routines in which a specific relationship between the comedian and the audience has an impact on what is considered impolite or rude (Locher \& Watts 2005). The present author's interest

to the performance, rendering a line more authentic or more forceful, and it helps to build a greater rapport with an audience (Seizer 2011).

10 Whilst it may not be polite, it complements the informal spirit of stand-up comedy.

11 It will also be shown later that to some extent it parallels the use in African American English.

12 For more information concerning the importance of context in which swearwords are used, see Beers Fägersten (2007).

13 This is a Lancaster University corpus toolbox for the analysis of language data. The software package has been downloaded from http://corpora.lancs.ac.uk/lancsbox/download.php (date of access 03/02/2020). 
in the analysis of this type of linguistic material also stems from his fascination with (African) American culture and language, colloquialisms and all that is informal in the language, an interest sparked and kindled by Professor Jacek Fisiak more than two decades ago.

This paper consists of two parts: the theoretical and the analytical. The first briefly introduces the nature of stand-up comedy, touching upon pragmatic considerations necessary in this context. Even though this paper is semanticallyoriented, the pragmatic aspect of the language of stand-up comedy warrants a brief explanation, ${ }^{14}$ and presents the reader with a potted history of the lexeme in question. In the analytical part, there is (i) a semantic analysis of shit as used in the Dave Chappelle's stand-ups supplemented with (ii) results obtained from the corpus of rap lyrics. ${ }^{15}$

\section{Theoretical background}

\subsection{Stand-up comedy}

Even though the paper deals with a semantic study of the lexeme shit, a short description of the comedic style that serves as the primary source from which language data have been harvested is appropriate. Stand-up is a type of a comedy in which theatrical stagecraft is kept to a bare minimum ${ }^{16}$ (Seizer 2011: 215) and where an on-stage comedian performs in front of an audience ${ }^{17}$ equipped solely with a microphone. Stand-up routines deal explicitly with a wide array of topics, ranging from current events, politics, sex, and taboos to the personal lives of the performers.

During stand-up performances the audience may have the impression of taking part in a dialog, whereas the performance consists of a quasi monolog interspersed with references targeted at people in the audience and moments aimed at evoking

14 I would like to express my gratitude to Dr. Piotr Jagodziński (Metropolitan University, Manchester, UK), without whom the paper would not have the present shape and whose expertise in the area of pragmatics was invaluable. I would also like to extend my thanks to prof. Michał Garcarz (University of Wrocław) for his valuable comments as well as to my former M.A. student, Ms. Martyna Zachorska, for her help in collecting literature on Dave Chappelle. Two reviewers' comments and remarks helped to improve the quality of the paper. All the plausible inconsistencies in the paper are solely mine.

15 Due to space limitations, the discussion of the material obtained from the rap corpus serves a supplementary purpose and is limited to the most common collocates of shit.

16 For more on the theatricality and anti-theatrical prejudice, see Barish (1981) and Seizer (2005).

17 The genre fundamentally requires an audience, and all broadcasts and recordings of stand-up comedy (be they on TV or streaming platforms), without exception, are made in front of a live audience (Brodie 2009). 
a response from them. Seizer (2011: 213) takes it further saying that although "it may be "heavily one-sided", it is nevertheless a dialogic form "that allows for reaction, participation, and engagement on the part of those to whom the stand-up comedian is speaking" (Brodie 2009: 4, as quoted in Seizer 2011: 213).

Seizer (2011: 214) also emphasizes the informal nature of a stand-up routine together with its intimacy. This is achieved both (i) by means of the comedians' standing "on stage at a microphone, positioned as the person in charge of the show", yet wearing "markedly casual attire, clothes to hang out in", ${ }^{18}$ and (ii) by peppering their speech with obscenities. The latter is

\begin{abstract}
... likewise a technique through which comics communicate an "off the record" attitude. This may make us feel, somewhat paradoxically, that the comedian speaks to us "from the heart." What does obscenity contribute to creating this sense of informality and intimacy in the comic's address? Several things. First, the majority of obscene words come from the source domain of sex and sex talk, and are born and reborn in that realm of intimacy. Taking these words out of the realm of the senses to use them in public address collapses the expected barrier between these experiential arenas, an incongruity that surprises. Likewise for those obscenities that are not explicitly sexual, but nonetheless refer to bodily functions and the stripped-naked basics of being human. Obscenities from both originary domains retain their power as big, bodily, experiential words used to convey basic human needs and feelings. In using them to creatively express their own feelings, comics combine self-exposure and intimate address with those critical "distances appropriate to humor" that allow for comment on our collective human condition (Bakhtin 1981, Seizer 1997) (Seizer 2011: 214).
\end{abstract}

Stand-up is not a new invention. It is over half a century old: "[t]he earliest origins of stand-up have been debated by a number of critics, but it is clear that in the 1950s and 1960s - precisely during the same era that saw the rise of American identity politics - the art began to resemble what we think of today" (Gillota 2015: 104). Gillota goes on to say that "performing in coffee shops and folk music clubs, humorists like Mort Sahl, Shelley Berman, Dick Gregory, and Lenny Bruce, among others, were the first well-known stand-ups ... Since then, the significance of stand-up has only continued to grow".

The 1980s witnessed an explosion of both stand-up clubs across the US and recorded stand-up specials on cable television. As time passed, some stand-up comedians launched their careers on television and in the cinema. Today's leading comedians frequently sell-out large auditoria, TV networks regularly air stand-up specials and streaming services such as Netflix and Amazon Prime, offer them in their repertoires.

18 Dave Chappelle achieves the sense of informality by engaging in impromptu short exchanges of jokes or by smoking cigarettes on-stage, sometimes cigarettes thrown onto the stage by members of the audience. 
African Americans have also been successful as stand-up comedians and their routines enjoy enormous popularity. They grow out of "a long tradition of subversive African-American folk humor" and it is there where the stand-up stage is used "to collapse the barriers for what could be said about race in a public forum. In their wake, African American stand-up became mainstreamed and profitable and also coalesced into a fairly recognizable collection of tropes and comic devices, such as comic impersonations of uptight white people" (Gillota 2015: 106). Gillota further writes:

\footnotetext{
Television series such as HBO's Def Comedy Jam (1992-2008) and BET's Comic View (1992-) were created to capitalize off of the success of African-American stand-up. Rather than focusing on and celebrating an individual performer, these shows featured a large and ever-changing roster of black comics who would perform relatively short sets in front of a mostly African-American studio audience. The individual comedians themselves were less important than the community they were there to represent. (2015: 106)
}

Comedians of African American provenance today fill huge auditoria, YouTube channels showing their videos are watched and subscribed to by millions and their revenues from streaming platforms are substantial. One surely cannot claim they are underestimated, as such names as Richard Pryor, Chris Rock, and Dave Chappelle cannot be ignored when discussing (the history of) American stand-up comedy. These names stand alongside such iconic comedians as George Carlin, Jerry Seinfeld, Bill Burr or Louis C.K. ${ }^{19}$

\subsection{Stand-up comedy: Pragmatic considerations}

The focus of this paper demands that, before we move on to the more semantically oriented analysis of the lexeme shit, it is crucial to emphasize that Dave Chappelle does not use it in a pragmatic vacuum. As Jay (1992: 12) claims, "to understand the nature of literal versus emotional reference one has to look at sentences or utterances, not individual words. A pragmatic analysis demands recording how words are used in a particular context; one has to record how people swear at other people in the real world". The context of stand-up comedy, the physical setting and the power dynamic between the comedian and the audience all clearly contribute to the way the lexeme in question is used and the kind of effect it has on the audience (both those in the room and TV audiences) and the way it is interpreted. The context of a stand-up comedy act enables Dave Chappelle to use

19 Their names are ranked among the funniest American comedians of all time in Internet rankers, see for example https://www.ranker.com/crowdranked-list/the-funniest-stand-upcomedians-in-entertainment (date of access 20/03/2020). 
the kind of language, including a variety of taboo words and phrases, that under different circumstances would be forbidden.

Stand-up comedy routines may usefully be encapsulated by the notion of activity type (Levinson 1992), which would understand stand-up comedy as a conventionalized collection of bound speech acts (cf. Archer et al. in press). It would emphasize the constraints regarding permissible contributions and the existence of pre-defined expectations on participants. These expectations structure the inferences drawn by the audience. It is safe to say that within the stand-up comedy activity type, the use of obscene language is not only allowed but also clearly expected by the audience. This is in line with the central assumption behind the notion of the activity type, i.e., that language both shapes and is shaped by context (cf. Culpeper \& McIntyre 2010). Thomas (1995: 190-192) provides a useful checklist for the description of activity types in terms of i) participants' goals, ii) permissible contributions, iii) the degree to which Gricean maxims are adhered to or are suspended, iv) the degree to which interpersonal maxims are adhered to or are suspended, v) turn-taking and topic control, and vi) the manipulation of pragmatic parameters. The participants' goals are primarily to entertain the audience and secondarily to provide social commentary on an array of (sensitive) topics, including, but not limited to, race relations and class issues, to name but two.

In terms of the permissible contributions it is fair to say that the audience expects that the performer will explicitly mention topics that would be considered taboo in other activity types. Stand-up comedy is therefore characterized by the expectation of vulgar or otherwise explicitly offensive types of language (see examples below). In terms of the degree to which Gricean maxims ${ }^{20}$ are adhered to, Chappelle's language may be characterized by clinging to the maxim of quality insofar as he relies on explicit descriptions rather than on generating implicatures. In terms of the interpersonal maxims, Chappelle seems to rely on maximizing the expression of beliefs which express the disapproval of others (cf. the approbation maxim), as well as maximizing the dispraise of others (cf. the modesty maxim). The last two points on the checklist that have to do with turntaking and the manipulation of pragmatic parameters, by the very nature of standup comedy are controlled by the comedian who holds the floor, and the audience possesses too little power to manipulate pragmatics parameters in terms of increasing or reducing social distance.

20 These are: "the maxim of quantity, where one tries to be as informative as one possibly can, and gives as much information as is needed, and no more. The maxim of quality, where one tries to be truthful, and does not give information that is false or that is not supported by evidence. The maxim of relation, where one tries to be relevant, and says things that are pertinent to the discussion. The maxim of manner, when one tries to be as clear, as brief, and as orderly as one can in what one says, and where one avoids obscurity and ambiguity" (https://www.sas.upenn.edu/ haroldfs/dravling/grice.html; date of access 06/01/2020). 
Building on the last point on the checklist, the context of stand-up comedy is interesting in terms of the way the comedian manages or navigates face considerations. These considerations tend to go beyond the use of the lexeme shit. The various senses of this lexeme as deployed by Chappelle, however, carry a significant face-threatening potential both for the audience and for the comedian. This is part and parcel of this activity type, i.e., the group face of the audience and the face of its individual members are threatened and attacked (cf. Bull et al. 1996). Given the constraints of this particular activity type and its conventions, however, the attack does not always result in an offence. The impoliteness deployed is often the source of humor, serves the purpose of emotional venting, and provides social commentary on the part of the comedian. As will become clear in the corpus analysis and the data extracts below, the audience is not usually the direct addressee of Chappelle's face threats and face attacks. To provide a full picture of the interactional dynamics of the stand-up comedy activity and the potential types of offence that might or might not be taken it is necessary to describe it in terms of the respective statuses of the participants, as hearers/listeners, addressees, and overhearers (cf. Dynel 2012). Inasmuch as this complexity is acknowledged, given the semantically oriented analysis undertaken here, it is beyond the scope of this paper to develop those issues further.

\subsection{Colloquial/slang semantics}

Some of the words deemed taboo and those proscribed by society, with the passing of time, especially when used colloquially or in slang, ${ }^{21}$ tend to undergo one of two processes: amelioration (semantic bleaching) or pejoration. Amelioration sees lexical items develop more felicitous senses. A case in point might be awesome, which used to mean, and still means, especially in British English, "terrifying, awe-inspiring", but today its use in informal American English has marginalized this meaning, which has given way to one roughly equivalent to cool. The same phenomenon is in operation in the case of wicked,

21 Unlike informal language, the language used mainly in informal/unofficial contexts to communicate with the family or friends, slang is a counter-language. "Born in the street, it resists the niceties of the respectable. It is impertinent, mocking, unconvinced by rules, regulations and ideologies. It is a subset of language that since its earliest appearance has been linked to the lower depths, the criminal, the marginal, the unwanted or even persecuted members of society... slang is vibrant, creative, witty, and open to seemingly infinite re-invention. It is voyeuristic, amoral, libertarian and libertine. It is vicious. It is cruel. It is self-indulgent. It is funny. It is fun. Its dictionaries offer an oral history of marginality and rebellion, of dispossession and frustration. They list the words that have evolved to challenge those states. It is supremely human" (Green 2015: 5-6). 
$i l l$, sick, bad, and dope, all of which, together with the primary meaning, have developed a new, positive sense. ${ }^{22}$

Pejoration ascribes new, unfavourable meanings to a lexical item. Mattiello (2008: 45) discusses, for instance, the semantically neutral adverb inside, whose meaning in Standard English is "on the inner side". When, however, used in the context of prison, it denotes "in jail".

These processes are closely connected with the broadening or narrowing of the meaning and the meaning shift. ${ }^{23}$ The new denotation of the above lexical items broadens their meanings. If the meaning acquired in colloquial or slang use, for instance, begins to prevail over time, the primary meaning might be lost. As a result, meaning shift takes place. A classic example would be the word gay, whose slang meaning ousted the primary meaning and gay is rarely used in its dated senses of "happy", "light-hearted", "carefree", or, of a place, "attractive" and "in bright colors".

In tandem with the semantics of slang and expletives, overuse of words with emotive senses (described below) means that they "tend to be dephlogisticated" (Mencken 1963: 399) or, in other words, lose their intensity. During the past decades, as Hughes (2015 [2006]: 301) points out, this weakening has affected a number of terms

\begin{abstract}
derived from genital and excretory functions [which] have become toned down to mean nothing more offensive than "a worthless person" or "a fool." This trend can also be seen in the terms arse, arsehole, asshole, fart, shit, cunt, and prick. Weakening is apparent both in the more specifically British English swearwords twat, berk, and prat, as well as those of a more American provenance, such as cocksucker, motherfucker, and plain fuck used as a noun. The trend also incorporates general terms like British English bastard, sod, and git, as well as American English punk and son of a bitch. It is also apparent in the grammatical extensions to the verbal formulas fuck off and piss off, as well as the adjectives fucking and sodding.
\end{abstract}

\title{
2.4. Connotative and denotative meanings
}

The notions of connotative and denotative meanings ought to be briefly explained. The so-called "dirty words" are used to express connotative meaning, "such as the emotional overtones of a word, the feelings, moods, attitudes and power that is comprehended along with the denotative referent. Connotation is not specific or well-defined relative to denotation" (Jay 1992: 10). Denotation, in

22 Such cases run contrary to the ephemeral character of slang meanings. Apparently in the cases above (but for the positive meaning of $\mathrm{bad}$ ) novel meanings are by no means short-lived.

23 The latter may also be referred to as the semantic shift and is seen as another process that characterizes the formation of slang. It takes place when a word acquires a new meaning while keeping its old meaning. 
turn, "involves truth, analysis, intention, significance or synonymity; connotation is conveyed meaning involved in irony, sarcasm, understatement, overstatement, humor, idiomatic usage and implied requests. Connotative reference can occur with both taboo and nontaboo words, just as both can be used denotatively" (Jay 1992: 10). Shit might thus be used denotatively to mean feces or the act of voiding the bowels. It may also be used in idiomatic, non-denotational, and nonreferential ways, e.g., in the phrase "“holy shit!" to refer not to the excrement of a deity, but rather to express the intensity of the speaker's own experience of awe, fear, or any other such wonderment" (Seizer 2011: 211).

\subsection{Dave Chappelle's comedy and obscene language}

Despite the synchronic change of the linguistic landscape of cinema and TV productions and the rise of streaming platforms, the genre probably most frequently associated with explicit language is stand-up comedy. As was mentioned in Section 2.2., by definition the language used by stand-up comedians is constrained by the general expectations associated with the stand-up activity type (Levinson 1992). In terms of allowable contributions (cf. Thomas 1995) comedians' performances are characterized by frequent use of taboo expressions. ${ }^{24}$ Among such comedians is Dave Chappelle, described by Lawrence (2009: 31) as perhaps one of the most "well-known and influential comedians of his generation".

Born in 1973 to a family of academics, Chappelle chose a different career path and eventually rose to fame as a comedian thanks to his stand-up specials, but more importantly the popular comedy sketch series Chappelle's Show (a program broadcast on Comedy Central between 2003 and 2006). In 2006 Chappelle quit the show under rather mysterious circumstances ${ }^{25}$ to return to show business upon signing a lucrative contract with Netflix some ten years later.

In his shows Chappelle pokes fun at various aspects of American pop culture and politics, but his fame derives primarily from his notoriety in exposing race relations in the USA. Especially striking in his approach to race are his attempts to challenge racial stereotypes by (on the surface) reinforcing them, and, by using taboo words relating to race.

24 As Seizer (2011: 212) observes, however, stand-up comedians might be divided into two categories: "clean" and "dirty" comedians; the former avoiding taboo language, whereas the latter regaling in it.

25 Lawrence (2009) speculates that Chappelle's departure from the show in 2006 was a result of a critical consideration of the possible damage that his sketches and the perpetuation of racial stereotypes, which find their explanation below, might have done to the Black community. A similar opinion has been formulated by Pérez, who claimed that Chappelle (as well as Pryor in the past) "took trips to Africa during periods of ideological crisis concerning their roles in perpetuating versus undermining racism through their work". This resulted in the cancellation of a \$50m contract with Comedy Central (Pérez 2013: 483). 
Laughter, as was indicated earlier, may also be evoked by dint not only of stereotypes, but also obscene language. ${ }^{26}$ This is true of Dave Chappelle's stage persona, as he is generally known for the said exposure of racism, but also notorious for his use of words and phrases deemed inappropriate in public discourse. His taboo-busting, not only in terms of topics parodied, but also the vocabulary used, is by no means novel or peculiar to his stand-up routines. "Lenny Bruce, George Carlin, and Richard Pryor ${ }^{27}$ are the shared reference points and touchstones here, each recognized as a creative comic genius who used taboo language to critical effect. Collectively they, along with others less oft-cited in recent literature on stand-up, changed the tenor of what was, and is now, possible on the American stand-up stage since the 1960s and 1970s (Zoglin 2008, Lewis 2006, Nachman 2004, Boskin 1997)" (Seizer 2011: 212).

Chappelle's sketches are packed with vulgar words and expressions, among which pussy, cock, fuck, and motherfucker are to be heard (see the analytical part of the paper). His stage persona is well aware of taboo breaching as the following example suggests:

(1) Is the word "pussy" offensive? [crowd] No! All right, just checking, just checking. I asked that crowd when we was in Denver, "Is the word 'pussy' offensive?" And the whole crowd said no, except for two people. One was a woman in the front, older than me, maybe around my age. Definitely a feminist. You know what I mean. Short haircut, plaid shirt. You know what I'm saying. And she didn't say it offended her. What she said is, she said, "I am uncomfortable with that word." And I was like, "Really? You?" And before I could ask her why, there was one guy in the balcony - I don't think he was saying this to me, but he said this. Everybody heard him say it. He goes, "It's delicious." I was like, "What?" I don't think I've ever heard pussy called delicious before in my life. Now, this is not to say that it's bad. But it's definitely an acquired taste. .... The word "pussy" is only offensive if you're older. People my age and younger, I don't think we even - We dance to that shit (The Age of Spin, 2017).

26 Blake (2018: 353) says that: "There are several areas of culture where taboo is encountered. There is a traditional expectation that we should be respectful in talking about religion and matters of patriotic moment such as the flag and the war dead, and over the last fifty years or so a consensus has emerged that it is taboo to be sexist, racist, homophobic, and the like. But there is one taboo area that is pervasive, and one where specific words are subject to strong taboo, and that is sexual activity and excretion, and it is this area that is the prime locus of comedy (Ross 1998: 65)".

27 Mooney (2009: 22) quotes Pryor "who never holds back on the street talk": "Yeah, I said the word shit. I said "shit" not to shock anyone but because I'm too old to stand up here and say "doo-doo." If you tell the truth, you know you say "shit," too. If you ain't said "shit" before, come out in the parking lot with me, and let me slam the car door on your hand. You'll say "shit" and "motherfucker" both. Shit! Motherfucker!". 


\subsection{Dave Chappelle and the hip-hop community}

Chappelle's associations with hip-hop culture cannot be underestimated. He is well-known not only for his respect for rappers and their music ${ }^{28}$ but also the socio-political movement associated with hip-hop culture. Yates (2009) argues that Chappelle is not only a comedian fascinated with the rap scene, but a hiphop artist himself. She points to the fact that Chappelle's sketches, filled with stereotypes, archetypes, Whites' visions of African Americans and those of Blacks themselves serve as a valuable social commentary, which, just like hiphop, is a message from the African American community to the rest of the world. Both rappers and Chappelle also value authenticity, or, to use the African American term, they cling to "keeping it real". In this "philosophy", people should not moderate their views and modify the way they express themselves in search of acceptance by the mainstream white audience, but rather remain true to their own unique selves. As Yates (2009) claims, Chappelle reconciles the two extremes: on the one hand, he is able to maintain his credibility and authenticity, and, on the other, he still appeals very much to the mainstream. ${ }^{29}$ For both Chappelle and hip-hop/rap artists the mainstream (white) audience is not the main target group. As in the case of hip-hop, where "the streets" (Black community) have to "feel" an artist's music, Chappelle's comedy has to appeal to African Americans first. It needs to resonate on the "local level" because it speaks from the "local level" - only in such a case does the message maintain its authenticity. If not, it may spread to the "national level", which seems to parallel hip-hop, which is both local and national (Yates 2009).

Hip-hop also brought the underground black culture to the masses, contributing to profound social changes, including the election of the first African American president (cf. Balliu 2015). So does Chappelle's comedy, which "demonstrates the way in which hip-hop as a Black Arts legacy contributes positively to society to powerfully transform 'the' mainstream" (Yates 2009: 155).

References to rap artists are present in Chappelle's routines. Examples 2-4 are illustrative of this:

(2) You know, when I was growing up, I was probably about eight years old, and at the time, we were living in Silver Spring. Yeah. Yes. Common misconception about me and DC, a lot of people think I'm from the 'hood'. That's not true. But I never bothered to correct anybody... because I wanted the streets to embrace me. As a matter of fact, I kept it up as a ruse.

28 Recently, either at the beginning or at the end of his Netflix shows he pays tribute to rap music and hip-hop artists.

29 In a vein similar to the "big names" in the world of rap and hip-hop. 
Like sometimes I'll hang out with rappers like Nas and them, and these motherfuckers start talking about the projects (Equanimity, 2017).

(3) Well, if you saw it, I wasn't drunk. I had smoked some reefer... with some rappers. Yeah. I don't know if you know anything about hanging out with rappers, but their weed is very strong, stronger than what I was accustomed to (The Age of Spin, 2017).

(4) And for the hip-hop fans in the building... put two fingers up in the air for A Tribe Called Quest and my man Phife Dawg. May he rest in peace forever and ever. Thank you for that beautiful music. Good night, everybody. Thank you. Twos up! Twos up! Hands up, hands up! Twos up! We're gonna do this for Phife! I need everybody to rap with me right now! (The Age of Spin, 2017).

This link between Dave Chappelle and hip-hop culture and rap music is not mentioned incidentally. The worlds of comedians and rappers seem intertwined; the working hypothesis in the present paper is that his use of the lexeme shit derives from (or parallels) that found in rap lyrics. This hypothesis might find its justification in the theory of low- and high density networks; the hip-hop community may be seen as the latter, a closely knit group with the capacity for working as a norm-enforcement mechanism (Milroy \& Margrain 1980: 48). It is hoped that this hypothesis will find its verification in the sections below.

\section{The lexeme shit: Its past and present}

The lexeme is common enough in publications dealing with profanity, obscenity, swearing, and "bad" or "offensive" language (cf. McEnery 2006; Seizer 2011; Hughes 2015 [2006]) and it has long been considered a part of the latter. Before the discussion proper of its history and present-day usage, the term "offensive language" warrants a brief discussion. As the term suggests, ${ }^{30}$ it is language considered by certain opinion-forming segments of society as offensive, rude or impolite. Battistella (2005: 72) posits that "objections to obscenity and vulgarity in public language often focus on the idea of protecting some listeners from bad language. Stereotypically it is women and children who are assumed to need such

30 Other terms are "foul", "obscene", or "dirty" language. Interestingly in the context of this paper one term, dating from the mid- $13^{\text {th }}$ century, was "shit worde" - probably the "earliest categorization of coarse speech, followed by "foul speech," recorded from about 1455" (Hughes 2015 [2006]: 182). 
protection". ${ }^{31}$ Battistella (2005: 83) also observes an interesting parallel between offensive language and grammar. Both position "its users with respect to the perceived mainstream. Avoiding coarse language in public signals an understanding of the boundary between public and private discourse and a tacit acceptance of that boundary. Another parallel to grammar is the ethical nature of language identified by George Phillip Krapp. To be a speaker of good English, one must think about usage. This entails using language reflectively as opposed to reflexively" (Battistella 2005: 83).

Offensive language ${ }^{32}$ is not a homogenous entity and may be divided, in accordance with Battistella (2005: 72), into: (1) epithets, embracing a variety of slurs not only referring to race, ethnicity, gender, and sexuality, but also those that may refer to "appearance, disabilities, or other characteristics", e.g., such epithets as midget, gimp, or retard; (2) profanity, being tantamount to religious swearing or the "coarse use of what is taken to be sacred" (e.g., hell, damn, or, in Battistella's terms, a more emphatic goddamn); and (3) vulgarity and obscenity. Battistella (2005: 72) describes the latter in the following terms:

\footnotetext{
Vulgarity and obscenity refer to words or expressions which characterize sexdifferentiating anatomy or sexual and excretory functions in a crude way, such as shit and fuck, with the distinction between vulgarity and obscenity being primarily a matter of degree and prurience. The categories of epithet, profanity, and vulgarity/obscenity are not exclusive and compound expressions may belong to more than one category, as in the exclamation God fucking dammit.
}

Shit, whose primary meanings, according to the $O E D$ (s.v. shit, n. 1a, 1b, and v.), are "diarrhoea, excrement from the bowels, dung, a piece of excrement, to void (as) excrement, to defile with excrement", has a relatively complex history. It involves a semantic evolution from a word denoting (the act of) excretion, excrement, piece of dung, diarrhea, ${ }^{33}$ through a lexeme which in the course of Early Modern English began to acquire emotive force, a metaphorical use in reference to a despicable person, ${ }^{34}$ something regarded as worthless (the $O E D$ s.v. shit, n.), a coarse swearword carrying a vulgar or obscene (excretory)

\footnotetext{
31 "This stereotype was evident in the 1999 conviction of the so-called cursing canoeist, a man fined $\$ 100$ for violating an 1897 Michigan law that banned swearing in front of women and children. The rationale for men not cursing in the presence of women is apparently a nineteenth-century version of decorum" (Battistella 2005: 72).

32 For arguments for and against offensive language see Battistella (2005: 77-78).

33 "Shit would be a common term in Saxon for diarrhea, as it still is in rural dialects, and in the vulgar expression "to have the shits"” (Hughes 2015 [2006]: 432).

34 As Hughes (2015 [2006]: 432) writes, "Captain Francis Grose has shitsack in his Classical Dictionary of the Vulgar Tongue (1785) as an epithet for "a dastardly fellow: also a nonconformist"”.
} 
denotation often used metaphorically, ${ }^{35}$ to a lexeme whose meaning underwent amelioration. This process led to its nominal use sometimes paralleling the semantically neutral word stuff (see the discussion below) or to its colloquial verbal use denoting a neutral thing (as in: I shit you not which corresponds roughly to I am not kidding you) or even a positive word, especially with an accompanying quantifier good (as in: this record is good shit). The general broadening of meaning stems from the immense popularity of shit (or its frequency, see the quote from Hughes 2015 [2006] below) not only in the vernacular, but also in African American slang, which eventually brought about a plentitude of figurative and abstract senses in which shit appears (see Green's Dictionary of Slang, s.v. shit).

Shit is semantically a problematic word - even setting aside a plentitude of collocates or compounds and phrases in which it may appear - that the exclamatory usage per se may have a multitude of interpretations, a fact observed by Hughes (2015 [2006]: 170): ““'Shit!” could express annoyance, surprise, pleasure, contempt, boredom, and a range of other feelings. As can be seen, the more common a word, the wider its range of uses, an axiom that G.K. Zipf has corroborated with the alarming statistic that except for a few core words, "different meanings of a word will tend to be equal to the square root of its relative frequency"”.

Hughes (2015 [2006]) further distinguishes between referential and emotive uses, the former being "essentially factual, formal, and concerned with conveying reality in a precise neutral fashion", while the latter "essentially conveys the speaker's or writer's feelings". Emotive use of language, including swearing, "shows greater latitude in meaning, creating problems of interpretation" (Hughes 2015 [2006]: 170). He further posits that

... the term shit has a whole range of expletive meanings and tones, expressing anger, surprise, frustration, even pleasure, whereas the notional synonyms excrement and feces are simply factual and limited in tone, thus having no swearing potential. This example demonstrates another general truth that native Anglo-Saxon terms have greater emotive potential, and classical terms correspondingly less. However, not all of the "four-letter" words are actually of Anglo-Saxon origin. Furthermore, meanings of basic swearwords vary according to speech community. Thus bastard has very different senses in American, Australian, and British English, as does motherfucker even in America. Fanny remains a source of transatlantic anatomical confusion, meaning "vagina" in British English but "the buttocks" in American English. As can be seen below, tail had a similarly confusing range of meanings in medieval times (Hughes 2015 [2006]: 252).

35 "A century ago expletives like damn and for God's sake were unmentionable in polite society, while cunt, fuck, and shit were completely taboo" (Hughes 2015 [2006]: 300). 
Hughes (2015 [2006]: 170) also maintains that alongside the extended range of meanings, "emotive terms acquire greater grammatical flexibility. Thus, to take a prime example, fuck has extended its grammatical function from being exclusively a verb in late Middle English to virtually every other part of speech". In its most emotive and personal uses this "flexibility extends to the incestuous improbability of motherfucker, finally attaining such physical impossibilities as "fuck off!" and "go fuck yourself!" ... Green's Slang Thesaurus (1999) lists forty-three different forms and idioms. In the past there were, not surprisingly, even more forms, such as fuckster, fuckish, and fuckable, which have passed out of use" (Hughes 2015 [2006]: 170).

In a similar vein, the use of shit as a swearword, unlike fuck, which has thus far attained almost complete flexibility (Hughes 2015 [2006]: 171), acquired a certain degree of flexibility and falls in four categories (after Hughes 2015 [2006]):

(a) personal, as in: "You (piece of) shit!"

(b) personal by reference: "The shit!"

(c) general expletive of anger, annoyance, frustration: "Shit!"

(d) capacity for adjectival extension: "shitty".

The folk perception of shit entails a further step in the semantic process. For some respondents, from whom Niedzielski \& Preston (2000) elicited pertinent responses, it carries no semantic load. Niedzielski \& Preston (2000: 268) maintain more specifically that in the folk perception such items as cool, shit, and fuck might hold no meaning; their major function in a given utterance may be considered emphatic. Niedzielski \& Preston (2000) further assert that "apparently a number of respondents believe that slang and obscenity perform such "meaningless" tasks. Similarly, what most linguists might see as "discourse markers" ... including such items as "well," "like," and "you know," are also regarded as meaningless, or, worse, "dumb" and "bad habits" ..." (2000: 268-269).

Hughes (2015 [2006]) nonetheless classifies shit as a swearword and writes that swearing per se, which might also be shocking in its ugliness, draws in fact "upon very powerful but incongruous resonators" and one of these resonators is the excretory whose notable examples are both turd and shit. 
Shit still cannot be used in polite conversation, ${ }^{36}$ but in the realm of everyday informal or slang English it is immensely popular. The semantic development parallel with that of the noun stuff, which often appears a euphemistic counterpart of shit, is presented in the table below: ${ }^{37}$

Table 1. Parallel semantic developments of shit and stuff in colloquial use and slang

\begin{tabular}{|c|c|c|}
\hline meaning: & shit & stuff \\
\hline narcotics, dope, intoxication or euphoriant substances & $\mathrm{x}$ & $\mathrm{x}$ \\
\hline $\begin{array}{l}\text { to do what is required or expected of one; to perform one's role } \\
\text { (to do one's ...) }\end{array}$ & $\mathrm{X}$ & $\mathrm{X}$ \\
\hline $\begin{array}{l}\text { to be experienced or knowledgeable in one's subject, profession, } \\
\text { etc. colloquial. (to know one's ...) }\end{array}$ & $\mathrm{X}$ & $\mathrm{X}$ \\
\hline $\begin{array}{l}\text { what is particularly appropriate to the situation; what is required } \\
\text { (that is the ...) }\end{array}$ & $\mathrm{X}$ & $\mathrm{x}$ \\
\hline something worthless, rubbish, worthless ideas, discourse or writing & $\mathrm{x}$ & $\mathrm{x}$ \\
\hline useless or uninteresting matters (the phrase:_and ... ) & $\mathrm{x}$ & $\mathrm{x}$ \\
\hline anything, appearing at the end of listed elements (_ and ...) & $\mathrm{x}$ & $\mathrm{x}$ \\
\hline $\begin{array}{l}\text { used loosely to denote any collection of things about which one is } \\
\text { not able or willing to particularize; material, matter, business. }\end{array}$ & & \\
\hline colloquial. (with or without the preceding epithet) & $\mathrm{X}$ & $\mathrm{X}$ \\
\hline money, cash & $\mathrm{x}$ & $\mathrm{x}$ \\
\hline stolen goods, forbidden goods smuggled into jail & $\mathrm{x}$ & $\mathrm{x}$ \\
\hline $\begin{array}{l}\text { not to give a ... (not to give a stuff used in Australian and New } \\
\text { Zealand slang) }\end{array}$ & $\mathrm{X}$ & $\mathrm{x}$ \\
\hline $\begin{array}{l}\text { of a person, lying, spinning a line, telling untrue tales of an } \\
\text { experience; unpleasant, distasteful (in the phrase: full of ...) }\end{array}$ & $\mathrm{x}$ & $\mathrm{x}$ \\
\hline
\end{tabular}

The lexeme stuff in isolation serves as no substitute for shit used in its more vulgar or obscene senses ${ }^{38}$ i.e., a coarse exclamation of annoyance or disgust (as in: (oh)

36 “... shit and turd are ancient native terms that have retained their insulting capacity up to the present. By contrast, the more formal terms ordure and defecation, which are classically derived, do not have this ability, although excrement was so used in earlier times, for instance, by the dramatist Ben Jonson (1572-1637). The same is obviously true of fuck as against copulate, bum as against posterior, cunt as against vagina, and cock as against penis" (Hughes 2015 [2006]: 387).

37 The definitions have been taken from both the $O E D$ (s.v. stuff; s.v. shit) and Green's Dictionary of Slang (s.v. stuff; s.v. shit) (both dictionaries are available online).

38 As Hughes (2015 [2006]: xxiii-Xxiv) would have it, "[i]ndeed, in some contexts word choice seems to be almost totally random and variable, as in "I couldn't give a damn/shit/fuck/two hoots"'. In other contexts, word choice has to be very precise to be effective. Thus a condemnatory comment such as "He's an obsequious little prick!" achieves its effect through the contrast of the high register obsequious with the low register prick, but if one were to substitute, say penis or cock, the impact would be lost. This instance illustrates an important point about linguistic usage peculiar to swearing; namely, that all synonyms in a given wordfield do not function equally and interchangeably as swearwords". 
shit!). Neither might it replace shit in the phrase to feel like shit "awful, horrible" or such compounds as shit-scared "extremely frightened" or shit-hot "unpleasantly enthusiastic, very skillful" where shit serves as an intensifier (Mattiello 2008: 82).

Other idiomatic phrases where no substitution may take place ${ }^{39}$ are the following: ${ }^{40}$ chicken shit "unimportant", "inadequate"; shit list (also s-list) "a list of people one considers distasteful, untrustworthy and otherwise unacceptable; similarly extended to places"41; pull shit "to do something low-down, treacherous, underhand".

As mentioned above, shit is extremely prolific when it comes to forming or being a part of compounds, phrases, and expressions. Green's Dictionary of Slang under the entry denoting the nominal usage of shit, lists 97 compounds containing the lexeme (from beshit to shit-worth), 35 general phrases in which it is used figuratively (from ain't shit to shit oh dear!), 32 verbs pertaining to literary or figurative uses of excrement (from do a shit to take shit), 27 verbs referring to objects or situations with negative connotations (from feel like shit to get shit of), and 38 comparatives (from as shit to up the shit). Altogether there are 229 slang or colloquial entries. This indicates the immense productivity of shit in the realm of informal language in its broad sense. It might also have a euphemistic counterpart: ish and isht (Smitherman 2006).

The word shit tends to find its linguistic application as a marker of informality and debasement (Mattiello 2008: 217). These two are described as follows:

\begin{abstract}
Informality and debasement are chiefly evident in general slang words, which are deliberately used by speakers to break with the neutral standard language and to reduce the level of discourse to familiar or low speech. They signal the speakers' intention to refuse conventions and their need to be informal, to ease social exchanges and induce friendliness.
\end{abstract}

Even though there is a growing number of more neutral, if not positive, meanings of shit, it is not a word used in the mainstream media. ${ }^{42}$ It is still avoided in polite discourse, but might have some currency in general conversation. It also marks its preponderance in movies and TV series, as well as stand-up comedy and song lyrics.

39 This list is by no means exhaustive.

40 Although mentioned by Smitherman (2006) in the African American English context, these are by no means confined to this sociolect.

$41 \quad$ Green's Dictionary of Slang (s.v. shit, n.).

42 Even though, according to the United States' Federal Communications Commission, such words as shit, bitch, and ass have been deemed inappropriate for broadcast (cf. Kaye \& Sapolsky 2004b), Cressman et al. (2009: 117) write the following: "Although profanity has existed throughout human history, it has recently lost much of its status as a taboo linguistic practice, "becoming more commonplace in everyday discourse as well as on network television' (Kaye \& Sapolsky, 2004a, p. 911)”. 


\section{Analysis}

\subsection{Introductory remarks}

The corpus of Dave Chappelle's stand-up specials consists of 60,892 tokens, 4,968 types, and 4,797 lemmas. Table 2 below presents the titles constituting the corpus of Chappelle's routines:

Table 2. Corpus of Dave Chappelle's routines:

$\left.\begin{array}{lccc}\hline \text { Title: } & \text { year } & \text { tokens } & \text { network } \\ \hline \text { Killing Them Softly } & 2000 & 7,561 & \text { HBO } \\ \text { For What It's Worth } & 2004 & 7,958 & \text { Showtime } \\ \text { Deep in the Heart of Texas } & 2017 & 9,658 & \\ \text { Equanimity } & 2017 & 8,353 & \\ \text { The Age of Spin } & 2017 & 9,173 \\ \text { The Bird Revelation } & 2017 & 6,904 \\ \text { Sticks \& Stones } & 2019 & 8,038 & \\ \text { Sticks \& Stones (Epilogue) } & 2019 & 3,247\end{array}\right]$

In order to give a fuller picture of Chappelle's use of items of "bad language", amongst which shit is to be found, the frequency of the supposedly profane ${ }^{43}$ lexemes has been assessed by means of the LancsBox program. The list of profane lexemes has been taken from literature (e.g., Cressman et al. 2009: 131) and the Internet. ${ }^{44}$ This list comprises not only swearwords, but also derogatory terms and racial slurs. These are: ass, bitch (bitching), cock (cocksucker), cum, cunt, damn, dick, fag (faggot), fuck (along with fucked and fucking), hell, motherfucker (motherfucking), piss, pussy, shit, tits (titties, titty, titty-fuck), whore, and the $n$-word (including both nigger and nigga). Figure 1 below presents the results retrieved: ${ }^{45}$

43 The use of the adverb "supposedly" is intended. It might be argued that such lexemes as bitch, motherfucker, nigga, and shit have lost, at least partially, their pejorative and taboo overtones through excessive use in colloquial language/African American English/rap language style.

44 See the discussion below concerning profanity in rap lyrics. We have also used the list of seven dirty words from the comedian George Carlin. Carlin's “seven words you can't say on TV" offers one well-known list of widely recognized swearwords: shit, piss, fuck, cunt, cocksucker, motherfucker, and tits. Swearwords are often described as "dirty" in English and other languages alike, their dirtiness metaphorically referencing their taboo status in most contexts (Moore, Bindler, and Pandich 2010)" (Moore 2012: 171).

45 These are relative frequencies per 1,000 words. 


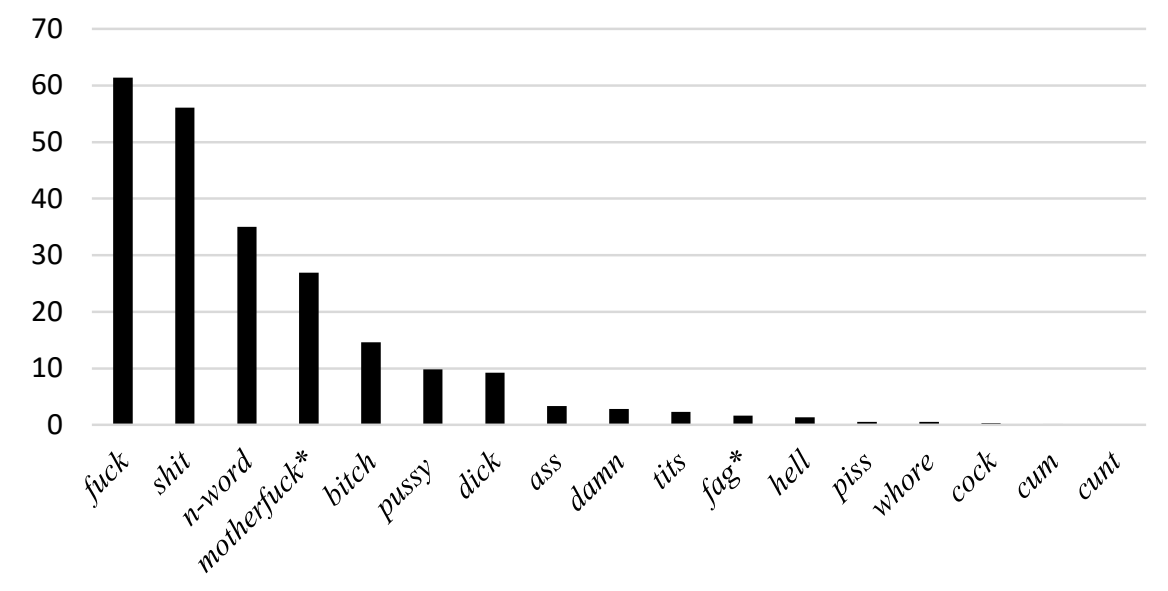

Figure 1. Bad language in Dave Chappelle's stand-up routines

The results obtained from the corpus correspond with the results garnered, e.g., from rap lyrics (see the discussion below). The lexeme fuck, interestingly, does not outnumber shit by a great deal, which might be due to the versatility and the multi-purpose nature of shit as used by Dave Chappelle's stage persona (see the elaborations on shit below).

As for shit, the LancsBox program allowed to retrieve its dispersion across the selected titles of Dave Chappelle's stand-up routines (see Table 3):

Table 3. The dispersion of shit across the chosen titles

\begin{tabular}{llccc}
\hline Title: & year & tokens & frequency & relative freq. per 10k \\
\hline Killing Them Softly & 2000 & 7,561 & 63 & 83.32 \\
For What It's Worth & 2004 & 7,958 & 62 & 77.91 \\
$\begin{array}{l}\text { Deep in the Heart of } \\
\text { Texas }\end{array}$ & 2017 & 9,658 & 58 & 60.05 \\
Equanimity & 2017 & 8,353 & 48 & 57.46 \\
The Age of Spin & 2017 & 9,173 & 47 & 51.24 \\
The Bird Revelation & 2017 & 6,904 & 33 & 47.80 \\
$\begin{array}{l}\text { Sticks \& Stones } \\
\text { Sticks \& Stones }\end{array}$ & 2019 & 8,038 & 34 & 42.30 \\
(Epilogue) & 2019 & 3,247 & 5 & 15.40 \\
\hline
\end{tabular}


As Table 3 shows, a diachronic decrease in the use of shit is observable in the corpus. The frequency of shit falls steadily between 2000 and $2019^{46}$, from 83.32 in 2000 to 42.3 in 2019 (taking into account the stand-up proper: Sticks \& Stones, and not the epilogue). The usage also varies among routines from the same year. In Deep in the Heart of Texas, the relative frequency per 10k nears 60.05, whereas in The Bird Revelation it drops to $47.80 .{ }^{47}$

In the remaining part of the paper we shall divide the occurrences of shit into three categories, somewhat overlapping with denotational and connotational meanings of the word:

I) primary or literal sense of either "excrement" (a shit) or "the act of defecation" (to shit);

II) an exclamation as an expression of annoyance, disappointment or anger as in shit! or holy shit!;

III) non-literal/figurative usage (this category is the most versatile and groups the demonstrative pronoun them shits $=$ these/those, idiomatic/phrasal/adverbial usage, for instance: shit happens,$^{48}$ as shit or metaphorical use, as in cold shit, and, finally, the usage of shit in the place of stufflnothing).

\subsection{Shit in Dave Chappelle's routines}

An inspection of the corpus yielded the data in Table $4: 49$

Table 4. Shit usage in the three categories

\begin{tabular}{ccc}
\hline primary sense & exclamation & figurative senses \\
\hline $6(1.7 \%)$ & $19(5.3 \%)$ & $325(93 \%)$ \\
\hline
\end{tabular}

As evident from the above table, the figurative usage clearly prevails, the rather conventional exclamation (holy/oh) shit! fails to pass the 6\% threshold. Shit in the literal sense of "a piece of excrement" and "an act of defecation" is also used here marginally (approximately 1.5\%). The discussion below begins with the use of shit in its primary sense. Whenever applicable, the discussion is supplemented with

46 Such a state of affairs might either be coincidental or it might stem from Chappelle's softening his language in Netflix productions.

47 This might be provisionally explained by the character of the target audience. In the routine originally performed in Texas Chappelle might have either built a better rapport with the audience by the use of words and expressions of a colloquial nature or he aimed at provoking the audience from an allegedly conservative state.

48 This phrase is used to express the observation that life is full of unpredictable events (Wikipedia, s.v. shit happens).

49 As a side note, shitty has not been recorded in this corpus. 
plausible equivalents/counterparts of shit. This is done in order to demonstrate the alleged commonness of this lexeme, which is characterized by informality and whose popularity causes it to oust other forms, also deemed informal.

\subsubsection{Shit used in its primary (denotational) sense}

The use of shit in its primary, scatological sense of voiding the bowels or (a piece of) faeces is marginal, to say the least. Out of six instances of shit in this sense three are verbal (see example 5), ${ }^{50}$ two nominal, and one phrasal (see examples 6 and 7 respectively):

(5) This motherfucker was rich. He used to shit in a gold toilet. It's true (Equanimity, 2017).

(6) Diarrhea has a bigger body count than the measles do. You know, diarrhea is funny today, but... a hundred years ago, if your ass had diarrhea, you were a goner. There was a zero chance of surviving. You get that first squirt. Pfft! Uh-oh. "Better start getting my affairs in order. I don't have much time. It's diarrhea. It's very serious." You just watch your buddy slowly die in a pool of his own shit. Pfft! (Deep in the Heart of Texas, 2017).

(7) "I have a shit streak on the middle of my shirt". How the fuck am I gonna explain this when I get home? "Oh, no, baby, me and Bob were playing basketball..." and Bob dunked on me... (For What It's Worth, 2004).

The limited number of attestations might be theme-dependent. It might be explained on the basis of that scatological themes, whilst present, do not dominate in Chappelle's stand-ups.

\subsubsection{Shit as an exclamation}

In the corpus there are only nineteen cases of the exclamatory use of shit. It is used there either in isolation (as in shit!, 3 cases recorded) or with an accompanying exclamation oh (as in oh shit, 12 cases recorded) or holy (as in holy shit, 4 cases recorded). All three usages are illustrated below:

(8) And then suddenly, a boxer rises from amongst them and reinstates their manhood with his motherfucking fist. This is not the guy you're supposed to ask, "What do you think of homosexuals?"He's not your champ. Shit. That's

50 In the corpus there is also one case of to crap. 
why I don't have a sneaker deal, 'cause if you say something that people don't like, they'll take your fucking shoes off (The Age of Spin, 2017).

(9) "Yeah!" The whole crowd banded together and started chanting, "We want our money back! We want our money back!" I said, "Oh, shit." I snapped out of it (The Age of Spin, 2017).

(10) We've had presidents before that have done bad jobs, but this shit is worse than a bad job. It's scary to watch. Holy shit. It's like seeing a crack pipe in your Uber driver's passenger seat (Equanimity 2017).

This exclamation may be replaced or rivalled by damn, an example of an allpurpose profanity, a milder version of shit. Such a replacement, however, is not always possible: shit cannot substitute damn in conjunction with God, i.e., God damn (*God shit is not possible). In the body of Chappelle's texts, therefore, there are twenty-four contexts permitting both shit and damn, the latter variant, however, is attested five times, accounting for $20.8 \%$ of the contexts. The usage is illustrated by example 11:

(11) In Utah last year, a 15-year-old girl Elizabeth Smart was kidnapped... then they finally found her and the whole country was relieved. And I was the only one saying, "Damn, she wasn't that smart after all". Not 'cause she got kidnapped (For What It's Worth, 2004).

\subsubsection{Shit in figurative sense}

We venture the claim that shit used idiomatically in current colloquial English is a rather distant relative of its pejorative predecessor. The residue of the offensive sense carried by shit is observable in such fixed phrases as "to talk shit" or derogatory reference to a person, as in "you piece of shit". The vast array of contexts in which we find shit in colloquial English mitigated its offensive connotation, so it has undergone the process of semantic amelioration. The great bulk of attestations retrieved from the corpus appears either in neutral or positive senses, which, at least in the context of Chappelle's routines, supports this claim. The degree of neutralness or positiveness is dependent either on the context in which it appears or on the preceding quantifier, or both (see examples 12 and 13 below).

(12) We spend the most time together. It's not that me and my wife don't spend time together, but we've been married so long, we don't talk like- I don't know if anyone's married here, but after ten years, all that chatty shit goes 
away. You've said it all. You know what I mean. Yeah. We're just in the zone. She says the same shit to me every night before she goes to bed. I'll be the last one up. She's like, "I'm gonna get some sleep, Dave. Good night" (Deep in the Heart of Texas, 2017).

(13) Not only were they not white, they were very, very black. They were Nigerian, which is the funniest shit. The whole story is funnier now (Sticks \& Stones, 2019).

The neutral usage might result from a certain similarity to the word stuff, whose more colloquial or slang equivalent shit appears to be (see Table 1). Both are onesyllable units with the same word-initial sound. In order to sound less formal, even congenial, to build a rapport with an interlocutor or just for humorous effect, one may use shit rather than stuff. The former also seems to have a broader range than the latter insofar as it may be used to replace nothing, anything, or the pronoun one in contexts where, at least stylistically, stuff would be inappropriate (see the discussion below).

The data show that in Dave Chappelle's stand-up routines the figurative use of shit constitutes the majority of attested instances at approximately 93\%, which amounts to 325 attestations. These attestations may be further subdivided in accordance with their morphology, the function they perform in a sentence, and the meaning they convey. Table 5 and Figure 2 show the breakdown figures for categories discussed in the subsections below:

Table 5. Various figurative (connotative) usages of shit in the corpus

\begin{tabular}{c|c|c|c|c}
\hline compound & $\begin{array}{c}\text { figurative } \\
\text { (negative } \\
\text { senses) }\end{array}$ & $\begin{array}{c}\text { (personal) } \\
\text { pronoun }\end{array}$ & $\begin{array}{c}\text { phrasal/idiomatic } \\
\text { usage }\end{array}$ & $\begin{array}{c}\text { stufflthing/ } \\
\text { anything/nothing } \\
\text { (neutral/positive } \\
\text { senses) }\end{array}$ \\
\hline $1(0.3 \%)$ & $6(1.8 \%)$ & $2(0.6 \%)$ & $14(4.3 \%)$ & $302(93 \%)$ \\
\hline
\end{tabular}




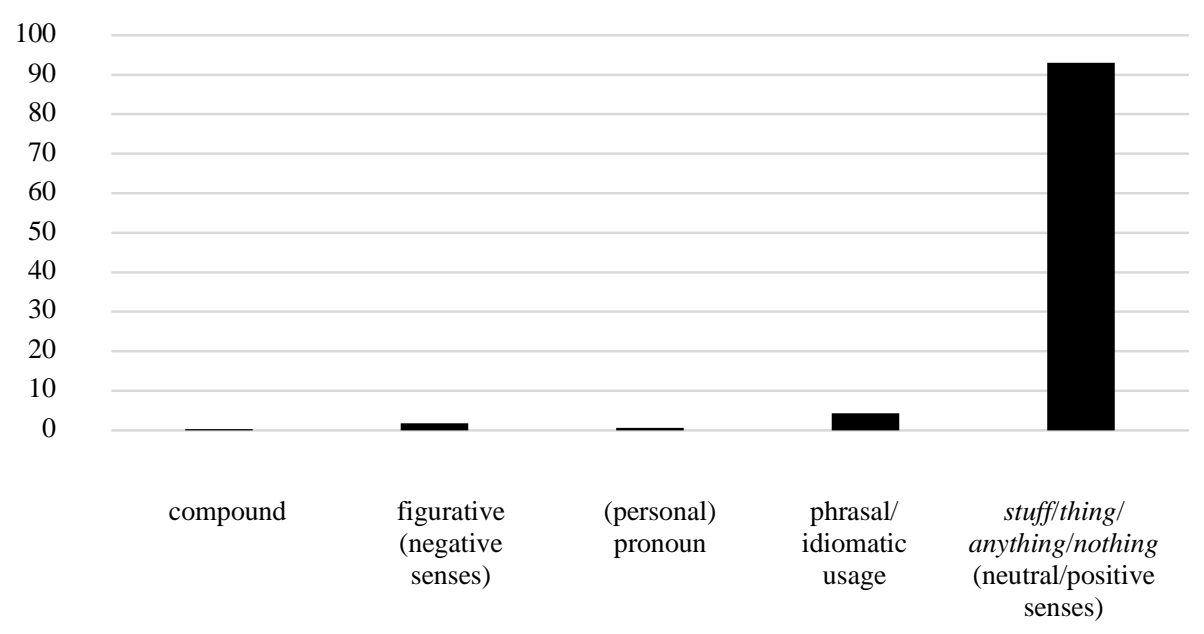

Figure 2. Various figurative (connotative) usages of shit in the corpus

\subsubsection{Compound}

Productive though shit may be as part of a compound (for a multitude of examples see Green's Dictionary of Slang, s.v. shit), in the corpus there is just one instance of a compound with shit: shitfaced. It is used in the sense of being under the influence of cannabis:

(14) “Listen, I'm fine. And don't forget you told me to do this. I'm at a party, and my designated driver had too much to drink. Me and my friends need you to come pick us up." I said, “Jesus Christ. It's one o'clock in the morning, nigga. I am shitfaced." But then I figured fuck, it's better me than some kid. I might as well roll the dice and go pick my nigga up. I said, "All right, I'm coming to get you. Give me the address and I'll be right there" (Equanimity, 2017).

Since this is an isolated instance, little may be said of compounds of the kind in Dave Chappelle's usage.

\subsubsection{Figurative (idiomatic) pejorative sense}

The pejorative figurative sense, presumably predating the newer, neutral/positive senses, and evidently stemming from the pejorative connotations usually elicited by faeces, clearly constitutes a marginal usage in the corpus (six cases out of $325=$ $1.8 \%$ ). Out of these, three instances of to talk shit/say shit about (the meaning of which is more or less equivalent to "talk aggressively about sb.", "to voice negative opinions about someone"), one of to get shit on sb. (in the sense of "heap criticism 
upon sb. or something"), and two of to treat sb. like shit ("treat sb. disrespectfully"). All of these usages are illustrated below:

(15) If somebody comes to your school and wants to shoot it up, I'm just gonna be honest with you. You probably gonna get shot, nigga. I'm just being real. You got a famous dad. I talk a lot of shit. They gonna be gunning for you, little buddy (Stick \& Stones, 2019).

(16) Sometimes I think that the media is hard on Trump. 'Cause I'll see shit that they get on him about that doesn't seem bad to me. Nigga got into trouble about not staying in the White House enough. Who gives a fuck? This motherfucker was rich (Equanimity, 2017).

(17) But now I'm watching it as an adult and I realize Sesame Street teaches kids other things: It teaches kids how to judge people and label people. That's right. They got a character on there named Oscar... and treat this guy like shit the entire show. They judge him right in his face (Killing them Softly, 2000).

In example 16, the use of shit might suggest a rather neutral meaning tantamount to stuff, but the context, or, to be more specific, the second clause, suggests that shit here carries pejorative overtones.

The scarcity of pejorative figurative senses is indicative of shit being well on its way to attaining the final stage of semantic bleaching, where the pejorative overtones are forced out by either the neutral or the positive sense (or both).

\subsubsection{3. (Personal) pronoun: them shits $=$ these/those/them}

This usage is intriguing, since thus far it seems to be unattested in existing dictionaries of either mainstream English or English slang. The only dictionary to provide a definition of them shits is the Urban Dictionary (s.v. them shits), whose reliability, unfortunately, may all too easily be undermined because the definitions and examples are provided by Internet users, who vote on their accuracy. The definitions provided are unverified by professional lexicographers. ${ }^{51}$ An obvious asset of this dictionary, nonetheless, is that it offers explanations of novel, hitherto unattested vocabulary, especially that originating in slang or colloquial usage.

51 These are also voted upon by other users, as a consequence of which the proposed definition that would seem to be considered the best is placed at the top of the page, but they are sometimes quite distant from the accepted usage as a result of, e.g., a prank. For current criticism of what used to be a repository housing millions of definitions of often recondite slang terms, see "What happened to Urban Dictionary" available at https://www.wired.com/story/urban-dictionary-20-years/. 
Them shits consists of the non-standard demonstrative them, which is a common trait of many dialects both in the British Isles (cf. Beal 1993: 207) and the US, and shit with a plural marker. The referent of them shits is a nominal phrase in the plural, as evident, for instance, in the examples obtained from the Corpus of Contemporary American English (see example 18):

(18) I'll rip your lips off and kiss my ass with them shits ("Blue Streak", 1999). ${ }^{52}$

In the corpus of Dave Chappelle's routines, the pronominal usage in reference to nominal phrases in the plural has been attested, as in the examples below:

(19) That shit sounds nuts. "I'm gonna go to China, and I'm gonna get those jobs from China and bring them back here to America." For what, nigga? So iPhones can be $\$ 9,000$ ? Leave that job in China where it belongs. None of us want to work that hard. What the fuck is he thinking? I want to wear Nikes. I don't want to make them shits. What the fuck are you doing? Stop trying to give us Chinese jobs (Equanimity, 2017).

(20) "Yo, nigga, let's go to the hospital and cut our dicks off and make pussies out of them shits" (The Age of Spin, 2017).

In both instances of Chappelle's usage there is a reference to a noun phrase in the plural. In (19) the referent is Nikes, in (20) our dicks. Even though both attestations allow for no further discussion, a quick search in the Corpus of Contemporary American English yielded 32 examples of such a usage in the time span 1994-2018. Apparently, the majority of these cases are used by African Americans or in African American-themed movies. An additional query, this time in the Corpus of Historical American English,${ }^{53}$ offered no earlier results which might suggest that the pronominal use of them shits is the product of the last decades of the $20^{\text {th }}$ century.

\subsubsection{Phrasal and idiomatic (rather neutral) usage}

The phrasal and idiomatic neutral usages of shit are confined to the following: (i) as shit, (ii) cold shit, ${ }^{54}$ and (iii) shit happens.

52 In Corpus of Contemporary American English (s.v. them shits). https://www.englishcorpora.org/coca, date of access 20/04/2020.

53 https://www.english-corpora.org/coha/, date of access 20/03/2020.

54 Even though the phrase in its entirety does carry pejorative overtones, shit deprived of the intensifier cold seems neutral, hence its inclusion here. 
(i) Green's Dictionary of Slang (s.v. as shit) provides the following definition of as shit: ${ }^{55}$ it functions as a "general intensifier", and might appear in, for example, mad as shit or good as shit. In the US campus usage, as attested by Eble (1973), the latter may also mean "very good":

(21) Yeah, he's smart as shit (P. Cornwell Last Precinct 238, in Green's Dictionary of Slang, s.v. as shit).

(22) good as shit! - terrific (Eble, Campus Sl., in Green's Dictionary of Slang, s.v. as shit).

In the corpus there are only seven occurrences of this phrase (in conjunction with high, scared, comfortable, quiet, happy, and mad):

(23) I looked at my sister, and she said, "I got the plates." And I was happy as shit because throwing a snowball at a motherfucker is a misdemeanor assault (Deep in the Heart of Texas, 2017).

(24) “Aaah!" Shit is scary as fuck. If your best friend pitched that to you, you'd be horrified (The Age of Spin, 2017).

In certain contexts, shit may be substituted by the lexeme fuck, in order to intensify the pragmatic impact of an utterance. The first phrase that allows for such an interchangeable use of shit and fuck is in fact the string with as. Green's Dictionary of Slang (s.v. as fuck, phrase, also a.f.) says that the adverbial use of fuck in this particular context serves, as in the case of as shit, the purpose of a general intensifier and may be treated as a coarse synonym for "as anything" (see example 25):

(25) We had burned a peach White Owl with Train Wreck in it, and so we were high as fuck (N. Walker Cherry 28, in Green's Dictionary of Slang, s.v. as fuck, adv.).

As indicated above, Chappelle is no intensive user of either as shit or as fuck. In the corpus of his routines, as well as the seven cases of as shit, there are only two recoded cases of as fuck (see example 26):

(26) But I knew that she was just really mad about that tape, so now she was gonna punish me about a fucking sandwich that I'd bit. I was mad as fuck (Deep in the Heart of Texas, 2017).

55 Which may also appear as a variant form as shite. 
The second phrase of the kind, where either shit or fuck might function, is to give a shitlfuck. In Green's Dictionary of Slang (s.v. give a fuck), the phrase give a fuck (also: to give a sweet fuck) is said to be of American provenance and carries the meaning of "to care about, to be concerned". It may also be used in a pejorative sense, e.g., who gives a fuck:

(27) I doubt if he gives a fuck about what I'm up to (N. Walker Cherry 12, in Green's Dictionary of Slang, s.v. give a fuck).

To give a shit is semantically similar to to give a fuck = "to care" and is also of American origin. Its pragmatic force, however, is reduced. As with its equivalent with fuck, it may be used in a pejorative sense, e.g., who gives a shit? or I could give a shit. In the corpus, there are eleven instances of to give a fuck (see example 28), but none with the lexeme shit.

(28) I don't give a fuck about interracial marriage. In fact, you know what? My mother is half white (Equanimity, 2017).

(ii) There are five occurrences of cold shit in the whole corpus. Examples 29 and 30 illustrate the context in which the phrase has been used:

(29) That's how the whole shit works, ladies. You understand? This bitch was at the end of her mileage. She was at for 498, she ended up tricking for Iceberg for another six months. She must have turned another 200 tricks for him. Do you understand? That's some cold shit. And the cold shit about it is that the dead guy on the bed wasn't even dead at all (The Bird Revelation, 2017).

(30) So he asks an older pimp how he can rein her in. And the older pimp says, "Oh, that's easy, Iceberg. All you have to do is beat that bitch with a coat hanger. And then run her a bath. And give her some pills. She'll be so grateful that you fixed her that she'll forget you were the motherfucker that beat her in the first place". That's some cold shit (The Bird Revelation, 2017).

The context in both examples suggests that the phrase is pejorative. It roughly translates as a fucked up situation. Cold shit is yet to be defined by, e.g., Urban Dictionary. The semantics and usage of the phrase are equivalent to cold game, the usage of which is exemplified below:

(31) That's some cold shit. And the cold shit about it is that the dead guy on the bed wasn't even dead at all. This motherfucker was just a friend of Iceberg's acting like he's asleep. The doctor wasn't a doctor. He was a 
motherfucking butcher that happened to have a white coat. And the dudes who came in the moving van clothes was dressed like movers because they were movers. Iceberg had gotten a new apartment. And the bag of money... was Iceberg's money in the first place. The money he got from all those women. That's a cold game (The Bird Revelation, 2017).

We took the liberty of quoting a longer chunk of Chappelle's monolog in order to show that cold game has been used here in exactly the same story as cold shit, hence the synonymous character of the two is evident.

Cold game, unlike its counterpart cold shit, has been attested in on-line dictionaries or websites that provide word/phrase definitions. For instance, the on-line site https://www.definithing.com/ gives the denotation of something being "plain f-cked up" and illustrates it with the following:

(32) d-mn dog, i was tryin to get that promotion and my boss gave it to someone else."

"that's cold game man." 56

Exactly the same denotation is given by Urban Dictionary (s.v. cold game). The phrase cold game per se has yet to find its way into Green's Dictionary of Slang. Among its definitions of the noun game, however, there sits one, "a situation, a state of affairs". Among the many definitions of cold one is clearly relevant to this context: "(US black/teen) unpleasant, difficult, unnecessary". This definition is illustrated by the following quote:

(33) One day, by and by, you will see the revolt of the Uncle Tom white people. That's some cold shit, man (G. Hasford Phantom Blooper 25 in Green's Dictionary of Slang, s.v. cold, adj).

(iii) shit happens

The phrase shit happens is, according to Green's Dictionary of Slang, "an allpurpose statement of resignation in the face of life's vicissitudes, i.e. these things happen; also euph..." (s.v. shit happens). The source provides the earliest attestation from 1978. The search of the Corpus of Historical American English yielded no earlier attestations, suggesting that this idiomatic usage of shit began in the last quarter of the $20^{\text {th }}$ century. The use of the phrase in the corpus is illustrated below:

56 https://www.definithing.com/ (s.v. cold game), date of access 03/03/2020. 
(34) You think when bad shit happens to me, I'll be in the crib like: "God, this is terrible. Could somebody please... find Ja Rule"? (For What's It Worth, 2004).

\subsubsection{Shit as an equivalent to stuff/thing/anything/nothing:}

As Figure 2 shows, shit in its neutral sense prevails in the corpus, comprising over $90 \%$ of the cases. It may function as a colloquial and sometimes jocular counterpart of stufflanything(nothing)/a thing (examples listed below illustrate these equivalents):

(35) Where you from, man? Hmm? Where you from?

New York.

You from what, Manhattan? Brooklyn. You are from Brooklyn, aren't you? You look like you can rob somebody with a hammer. Brooklyn niggas rob you with shit they find around the house. "I just got stabbed with a toothbrush. This nigga must be from Brooklyn" (The Bird Revelation, 2017).

(36) But then another time, me and Chip were driving. No I'm not driving. Chip is driving. And he's driving a little crazy. He's been drinking. I don't like to let my friends drive drunk. But you know I was smoking a joint. I couldn't really say shit to the guy (Killing them Softly, 2000).

(37) But lucky for me, that very same day, the Chicago police caught the motherfuckers that actually did it, and, hilariously, they were both, uh, Nigerian. Not only were they not white, they were very, very black. They were Nigerian, which is the funniest shit (Sticks and Stones 2019).

As a matter of fact, shit predominates over stuff $(295 / 301=98 \%),{ }^{57}$ whereas its usage to replace anything/nothing is mostly confined to a handful of idiomatic or quasi-idiomatic phrases $(6 / 301=2 \%)$ : say shit to somebody or not to know shit (see examples below):

(38) And I was furious. 'Cause nobody's saying shit to this guy. They was just looking like, "My God." I was the only one on the bus that had the balls to talk to him (For What It's Worth, 2004).

(39) You don't know shit! You gotta Google shit that I lived through (The Age of Spin, 2017).

57 For more information on shit as synonymous with stuff see the section below, in which the collocational behavior of the former is given. 
In comparison with shit, stuff is a minority variant with only ten attestations in the whole corpus. As the context suggests, the two lexemes might be used interchangeably, for instance: "I want that purple stuff/shit" or "all this stuff/shit is gross". Shit is the dominant variant form, since Dave Chappelle uses it far more often in his routines. Its usage might be governed by stylistic reasons. Shit, together with other informal and slang expressions, sounds "cooler" and more laid back, which corresponds to Chappelle's stage persona, and it induces the feeling of greater familiarity between the performer and his audience.

\section{Comparison with usage in hip-hop}

\subsection{Profanity in rap lyrics}

The Internet has websites which, thanks to the aggregation of song lyrics by means of "scraping techniques" and their automatized analysis, provide rankings of the most profane music lyrics representing a number of genres. ${ }^{58}$ The lyrics that contain most vulgarisms are rap lyrics. By means of example, the conclusions of the frequency research presented on the Musixmatch website ${ }^{59}$ state that

\footnotetext{
1 in every 47 words in Hiphop lyrics is a swear word. This also means every Hiphop song has 10 profanities on average. The top 3 swear words used are nigga, shit and niggas. But the ' $\mathrm{n}$ word' is generally not used in an offensive context in Hiphop. On removing it along with its conjugations from the analysis of Hiphop lyrics, 1 in every 74 words is a swear word in Hiphop lyrics. This still means 6 profanities in every song. Even with this reduction hip hop still remains the most profane genre overall.
}

That rap lyrics contain the highest number of swearwords of any genre of popular music is also attested by Moloney \& Sylva (2020). Whether such studies, based as they are largely on word-lists and frequencies and lacking in deeper consideration of the contexts in which the alleged vulgarities appear, really present profanity per se is unclear. ${ }^{60}$

Big data analytics apparently seem to take the lexemes at face value and neglect to delve into the semantic intricacies inextricably linked with the use of

\footnotetext{
For the use of profanity see https://rapalytics.com/. https://lab.musixmatch.com/profanity_genres/, date of access 02/02/2020.

60 More context focused studies show that the state of affairs is far more complex. For instance, in his scrutiny of fuck in gangsta rap lyrics, Dylewski (2019), who tapped into the broader sentence setting of fuck and its derivatives, showed that its use in idiomatic connotations, as an adverbial booster, (as in "fucking awful"), an emphatic adverb (as in "he fucking did it"), or an idiomatic phrase (as in "to fuck with somebody", "to give a fuck", "as fuck", for the fuck of something") outnumbered both the cursing expletive (fuck you), general expletive (fuck!), and the direct sexual use of fuck.
} 
words and phrases commonly regarded as taboo, whose intensive use in substandard or informal English has instigated semantic smoothing, if not a total semantic shift. It thus turns out that rap lyrics lead the way in terms of profanity and it comes as little surprise that the preponderance of shit occupies one of the top positions, third only to the words fuck and nigga (many authors acknowledge that when used by African Americans the latter is not a racial slur in the majority of contexts, but rather a neutral term).

Whether shit, when used by Dave Chappelle, American rappers or in informal and colloquial parlance, is a vulgarism or it may be considered alongside the neutral nigga and the figurative and idiomatic use of fuck is disputable; its current taboo status may be questioned: Trotta \& Blyahher, for example, in their 2011 article on the selected African American English traits in the TV series "The Wire", treat shit as a rough equivalent of nothing. Let us see the comparison between the most prevalent usage of this lexeme ${ }^{61}$ in the Chappelle Corpus and the corpus of rap lyrics to verify Trotta \& Blyahher's claim.

\subsection{The corpus of rap lyrics}

The corpus was compiled between 2017 and 2019 at the Faculty of English at the Adam Mickiewicz University in Poznan. ${ }^{62}$ It consists of 6,532 rap songs by 74 artists, amounting to 3,693,170 tokens. The lyrics were culled from https://www.genius.com/ and represent the subgenres of rap, whose lyrics are often confrontational, reflect the harsh realities of life in the ghetto, and are frequently replete with misogyny, sexual themes, and profanity.$^{63}$ The subgenres are gangsta rap, hard-core rap, and horrorcore. ${ }^{64}$ The lyrics garnered cover the time between 1980s and 2019, and are geographically diverse: they represent the hotbeds of American hip-hop activity and, therefore, the production of rap records: West Coast, East Coast, and Southern Rap. ${ }^{65}$

61 Space constraints mean a more elaborate discussion of the use of shit in the Rap Corpus must be forgone here. Shit as an exclamation appears rarely there. For example, we recorded 127 cases of oh shit (normalized freq. $=0.37$ ) and just four cases of holy shit $(=0.02)$.

62 The team responsible for its compilation consisted of Kinga Gołdyka, Diana Hovhannisyan, Natalia Nowaczyk, Julia Skrzypiec, and Radosław Dylewski.

63 Of course, not always, even though the lyrics of such self-conscious duos or bands as Dead Prez or Public Enemy are of a confrontational nature, the themes deal with social activism and are political and anti-establishment.

64 Space constraints mean that the finer differences between these three rap styles will be forgone here. For the sake of clarity, however, a few words of explanation are due. The stylistic differences between gangsta rap and hard-core rap run along the East Coast-West Coast axis. Horrorcore evolves from gangsta rap where supernatural or occult elements are added to the song lyrics.

65 For the precis of differences between the three major sub-genres of American rap - East Coast, West Coast, and Southern rap (sometimes called "Dirty South") - see https://curtismwest.wordpress.com/ 


\subsection{Shit in both corpora}

We have looked at those lexemes commonly regarded as profane in the Rap Corpus. Figure 3 presents superimposed datasets from both corpora.

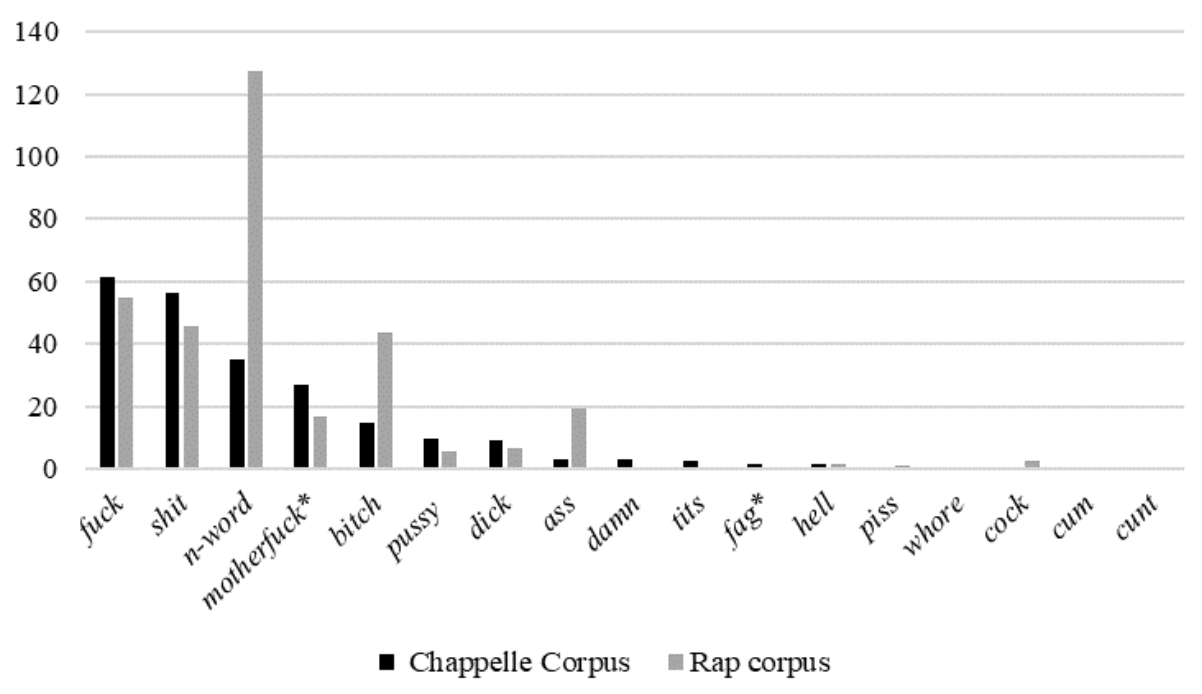

Figure 3. Profanity in the Chappelle and Rap Corpora

The greatest discrepancy between the two datasets is evident in the three lexemes, nigga, bitch, and ass. This discrepancy may be explained by the propensities of the corpus, which see the usage of the $n$-word thematically conditioned by rap lyrics, where this formerly racial slur (nigger), here in an altered spelling and r-less (nigga), enjoys tremendous popularity. ${ }^{66}$ The intensive usage of bitch comes as no surprise because this term is frequently used in the rap lyrics to depict misogynistic overtones. It ought to be noted that bitch does not always have pejorative connotations and its usage is not solely confined to contexts of the kind: especially when accompanied by a quantifier carrying positive overtones, bitch is used in a neutral context and its meaning approximates that of an 'attractive female'. As for ass, the lion's share of cases in the Rap Corpus are affixes used to form adjectives and occasionally nouns (Green's Dictionary of Slang, s.v. - ass, sfx.), as in bad ass bitch, amateur-ass niggas, big-ass truck, dirty ass clothes or clown-ass shit.

2012/04/15/how-hip-hop-music-differs-in-the-east-west-and-south/.

66 Especially in gangsta rap, which is notorious for its use of this word. Band names as well as lyrics have contributed to the popularization of nigga: N.W.A. is an acronym that stands for Niggas with Attitude. 
The difference between Chappelle's use of shit and that of rap parallels that of fuck (and its derivatives), motherfuck ${ }^{*}$ (and derivatives), pussy, damn and other, less popular words (see Figure 3). In all of these cases it is rap usage that leads the way and Chappelle's stage persona's usage lags behind.

In order to ascertain the collocational behavior of shit in both corpora, the LancsBox program was again utilized. The search was limited to a span of two words to the left of the node of interest. This approach has its drawbacks, but it allows for an avoidance of the retrieval of, e.g., collocations with $I$, as in I can see shit. The results thus obtained are as follows: the top five most common elements preceding shit in the Chappelle Corpus are demonstrative adjectives (that and this), and (as in and shit, meaning that "used to say that there are more details that you could mention, but it should be clear to someone else what you mean"67), some (as in "I have seen some shit"), and the. The Rap Corpus data are more or less parallel. The top five elements that precede shit are that, the, this, some and $m y$ (as in "I got my own shit). Pooled data for both corpora are presented in Table 6 and are illustrated graphically by Figure 4:

Table 6. The most frequent collocates of shit in the two corpora ${ }^{68}$

\begin{tabular}{lcccc}
\hline & \multicolumn{2}{c}{ Chappelle Corpus } & \multicolumn{2}{c}{ Rap Corpus } \\
\hline collocate: & raw numbers & normalized freq. & raw numbers & normalized freq. \\
\hline and shit & 36 & 5.91 & 509 & 1.38 \\
my shit & 4 & 0.66 & 673 & 1.82 \\
some shit & 12 & 1.97 & 372 & 1.01 \\
that shit & 117 & 19.21 & 1,618 & 4.39 \\
the shit & 11 & 1.81 & 1,416 & 3.83 \\
this shit & 41 & 6.73 & 1,515 & 4.1 \\
\hline
\end{tabular}

67 https://www.ldoceonline.com/dictionary/and-shit, s.v. and shit, date of access 22/03/2020.

68 Normalized to 10,000 words. 


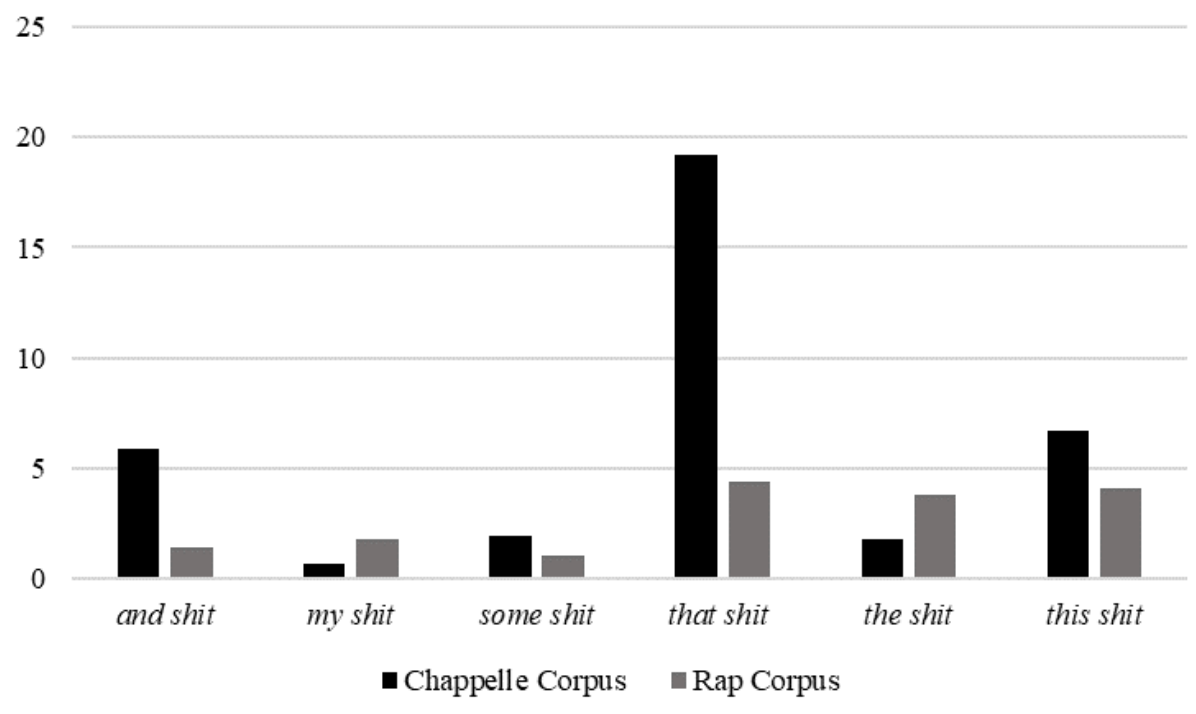

Figure 4. The most frequent collocates of shit

Even though we juxtapose the data obtained from two corpora which are of considerably different sizes, as well as stylistically and thematically diverse, the similarities in the collocational behavior of shit are conspicuous (see the concluding section of the paper). The preponderance of that shit in the Chappelle Corpus might be explained as follows: since the stand-up routine is based on story-telling for humorous effect, its cohesion is maintained by the repetitive use of such devices as that shit. It also serves the stylistic, referential purpose employed to, inter alia, keep listeners' attention and to avoid repeating the "same stuff". In general, the collocation is an anaphor to aid the flow the discourse. ${ }^{69}$

\section{Conclusion}

Jay (1992: 14) says the following in reference to the word condom: "[it] has apparently lost its taboo by constant and frequent usage. The repetition of a word thus blunts the original offense caused by inhibition or taboo. This desensitization effect is not particular to dirty words but occurs when any word is used repeatedly". This claim may be extended to the word shit. Shit is prominent among the 3,000 most frequently used words in English (Hughes 2015 [2006]: 75), which suggests that calling it taboo is a misnomer. Still, some 40 years ago shit, together with fuck,

69 The same situation takes place with the definite article the (as in "that is the shit"). 
cunt, and motherfucker (in varying orders) was rated as the "most offensive term (Baudhuin 1973, Bostrom et al. 1973, Driscoll 1981, Jay 1977, Mabry 1975)" (Beers Fägersten 2007: 15). The passing of time appears, at least in some contexts and especially when used connotatively, to have deprived it of its taboo status and it seems to be a marker of colloquial style and, in the case of stand-up comedians, it might be "used to add spice, to make a line more authentic or more forceful, to achieve greater rapport with an audience" (Seizer 2011, as quoted in Blake 2018: 355). It is also an element of informal language, be it African American English or the less mainstream varieties of American English.

This study has shown that shit, at least in the two corpora under scrutiny, is mainly used in its neutral and sometimes in positive denotations equivalent to stuff, which supports the claim of its semantic soothing. Dave Chappelle's stage persona's use corresponds to the use observable in the Rap Corpus. Bearing in mind that "most black rappers do use $\mathrm{AAVE}^{70}$ when communicating with one another" (Alim 2006: 74) and linguistic features of African American English are omnipresent in rap lyrics, ${ }^{71}$ we might venture the claim that Dave Chappelle, an African American himself, uses shit as it is used in the sociolect of African Americans. This use might also correspond to the informal usage in colloquial American English. Such a conclusion warrants verification, but a study of informal American English constitutes a topic in its own right.

\section{REFERENCES}

Alim, H. Samy. 2004. Hip hop nation language. In Edward Finegan \& John R. Rickford (eds.), Language in the USA: Themes for the twenty-first century, Cambridge University Press. 387-409. DOI: https://doi.org/10.1017/CBO9780511809880.023

Alim, H. Samy. 2006. Roc the mic right: The language of hip hop culture. Routledge.

Allan, Keith. 2018. Taboo words and language: An overview. In Keith Allan (ed.), The Oxford handbook of taboo words and language, Oxford University Press. 1-27. DOI: 10.1093/oxfordhb/9780198808190.013.1

Amdan, Nur Faatihah Binti \& Azianura Hani Shaari. 2017. An analysis of profanity in English lyrics. Jurnal Wacana Sarjana 1(1). 28.

Archer, Dawn, Piotr Jagodziński \& Rebecca Jagodziński. (in press). Activity types and genres. In Michael Haugh, Daniel Kadar \& Marina Terkourafi (eds.), Cambridge handbook of sociopragmatics. Cambridge University Press.

70 African American Vernacular English.

71 As Cutler (2007: 521) writes, "Over the past two decades sociolinguistics has identified a language ... associated with hip-hop consisting of a range of phonological, grammatical, and lexical patterns. Most of these are rooted in structures found in AAE, but others, especially hip-hop slang terms, are unique and continue to evolve". 
Bakhtin, Mikhail M. 1981 [1935]. Discourse in the novel. In Michael Holquist (ed.), The Dialogic Imagination: Four essays by M. M. Bakhtin (translated by Caryl Emerson \& Michael Holquist), University of Texas Press. 259-422.

Balliu, Sofie. 2015. The paradoxical position of the white rapper in hip-hop music: A genre fixated on authenticity. An analysis of the use of African-American English in the music of Eminem, Iggy Azalea, and Classified. An unpublished M.A. thesis, Universiteit Gent.

Barish, Jonas A. 1981. The anti-theatrical prejudice. University of California Press.

Battistella, Edwin L. 2005. Bad language: Are some words better than others? Oxford University Press.

Baudhuin, E. Scott. 1973. Obscene language and evaluative response: An empirical study. Psychological Reports 32(2). 399-402.

DOI: https://doi.org/10.2466/pr0.1973.32.2.399

Beal, Joan C. 1993. The grammar of Tyneside and Northumbrian English. In James Milroy \& Lesley Milroy (eds.), Real English: The grammar of English dialects in the British Isles, Longman. 187-213.

Beers Fägersten, Kristy. 2007. A sociolinguistic analysis of swear word offensiveness. Saarland Working Papers in Linguistics 1. 14-37.

Beers Fägersten, Kristy 2012. Who's swearing now? The social aspects of conversational swearing. Cambridge Scholars Publishing.

Blake, Barry J. 2018. Taboo language as source of comedy. In Keith Allan (ed.), The Oxford handbook of taboo words and language, Oxford University Press. 353-371. DOI: 10.1093/oxfordhb/9780198808190.013.19

Boskin, Joseph. 1997. Rebellious laughter: People's humor in American culture. Syracuse University Press.

Bostrom, Robert N., John R. Baseheart \& Charles M. Rossiter Jr. 1973. The effects of three types of profane language in persuasive messages. Journal of Communication 23(4). 461-475. DOI: 10.1111/j.1460-2466.1973.tb00961.x

Brezina, Vaclav. 2018. Statistics in corpus linguistics: A practical guide. Cambridge University Press.

Brodie, Ian Bernard. 2009. Stand-up comedy: A folkloristic approach. Unpublished Ph.D. dissertation, Department of Folklore, Memorial University of Newfoundland.

Bucaria, Chiara. 2017. Audiovisual translation of humor. In Salvatore Attardo (ed.), The Routledge handbook of language and humor, Routledge. 430-443. DOI: $10.4324 / 9781315731162 . c h 30$

Bull, Peter, Judy Elliott, Derrol Palmer \& Libby Walker. 1996. Why politicians are three-faced: The face model of political interviews. British Journal of Social Psychology 35(2). 267-284. DOI: 10.1111/j.2044-8309.1996.tb01097.x

Cressman, Dale L., Mark Callister, Tom Robinson \& Chris Near. 2009. Swearing in the cinema: An analysis of profanity in US teen-oriented movies, 1980-2006. Journal of Children and Media 3(29). 117-135.

Culpeper, Jonathan \& Dan MacIntyre. 2010. Activity types and characterisation in dramatic discourse. In Jens Eder, Fotis Jannidis \& Ralf Schneider (eds.), Characters in fictional worlds: Understanding imaginary beings in literature, film, and other media, Walter de Gruyter. 176-207. DOI: 10.1515/9783110232424.3.176

Cutler, Cecelia. 2007. Hip-hop language in sociolinguistics and beyond. Language and Linguistics Compass 1(5). 519-538. DOI: 10.1111/j.1749-818X.2007.00021.x

Driscoll, James M. 1981. Aggressiveness and frequency-of-aggressive-use ratings for pejorative epithets by Americans. The Journal of Social Psychology 114(1). 111-126. DOI: https://doi.org/10.1080/00224545.1981.9922733 
Dylewski, Radosław. 2019. Semantic bleaching? A study of the f-word in the corpus of (gangsta) rap lyrics. Presentation delivered in April 2019 at the Faculty of English at Adam Mickiewicz University in Poznań.

Dynel, Marta. 2012. Setting our House in order: The workings of impoliteness in multi-party film discourse. Journal of Politeness Research 8(2). 161-194. DOI: 10.1515/pr-2012-0010

Eble, Connie. 1973. Slang and sociability: In-group language among college students. The University of North Carolina Press.

Gillota, David. 2015. Stand-up nation: Humor and American identity. The Journal of American Culture 38(2): 102-112. DOI: 10.1111/jacc.12301

Green's Dictionary of Slang. Available at https://greensdictofslang.com.

Green, Jonathon. 1999. The slang thesaurus (2nd edn.). Penguin Books Ltd.

Green, Jonathon. 2015. The vulgar tongue: Green's history of slang. Oxford University Press.

Hughes, Geoffrey. 2015 [2006]. An encyclopedia of swearing: The social history of oaths, profanity, foul language, and ethnic slurs in the English-speaking world. London \& New York: Routledge.

Jay, Timothy. 1977. Doing research with dirty words. Maledicta: The International Journal of Verbal Aggression 1. 234-256.

Jay, Timothy. 1992. Cursing in America: A psycholinguistic study of dirty language in the courts, in the movies, in the schoolyards and on the streets. John Benjamins. DOI: https://doi.org/10.1075/z.57

Jay, Timothy \& Kristin Janschewitz. 2008. The pragmatics of swearing. Journal of Politeness Research 4(2). 267-288. DOI: 10.1515/JPLR.2008.013

Kaye, Barbara K. \& Barry S. Sapolsky. 2004a. Talking a "blue" streak: Context and offensive language in prime time network television programs. Journalism \& Mass Communication Quarterly 81(4). 911-927. DOI: https://doi.org/10.1177/107769900408100412

Kaye, Barbara K. \& Barry S. Sapolsky. 2004b. Watch your mouth! An analysis of profanity uttered by children on prime-time television. Mass Communication and Society 7(4). 429-452. DOI: https://doi.org/10.1207/s15327825mcs0704_4

Lawrence, Novotny. 2009. Comic genius or con man? Deconstructing the comedy of Dave Chappelle. In Kevin A. Wisniewski (ed.), The comedy of Dave Chappelle: Critical essays. McFarland \& Company, Inc. 31-46.

Levinson, Stephen C. 1992. Activity types and language. In Paul Drew \& John Heritage (eds.), Talk at work: Interaction in institutional settings, Cambridge: Cambridge University Press. 66-100. [originally published in 1979 in Linguistics 17(5-6). 365-399.]

Lewis, Paul. 2006. Cracking up: American humor in a time of conflict. The University of Chicago Press.

Locher, Miriam A. \& Richard J. Watts. 2005. Politeness theory and relational work. Journal of Politeness Research 1(1). 9-33. DOI: 10.1515/jplr.2005.1.1.9

Mabry, Edward A. 1975. A multivariate investigation of profane language. Central States Speech Journal 26(1). 39-44. DOI: 10.1080/10510977509367817

Mattiello, Elisa. 2008. An introduction to English slang: A description of its morphology, semantics and sociology. Polimetrica.

McEnery, Tony. 2006. Swearing in English: Bad language, purity and power from 1586 to the present. Routledge.

Mencken, Henry Louis. 1963. The American language. (Abridged and edited by Raven I. McDavid Jr.) Knopf. 
Milroy, Lesley \& Sue Margrain. 1980. Vernacular language loyalty and social network. Language in Society 9(1). 43-70. DOI: 10.1017/S0047404500007788

Moloney, Martin James \& Hanifah Mutiara Sylva. 2020. ““And I swear...' - Profanity in pop music lyrics on the American Billboard charts 2009-2018 and the effect on Youtube popularity. International Journal of Scientific \& Technology Research 9(1). 52125220.

Mooney, Paul. 2009. Black is the new white. With a foreword by Dave Chappelle. Simon Spotlight Entertainment.

Moore, Robert L. 2012. On swearwords and slang. American Speech 87(2). 170-189. DOI: $10.1215 / 00031283-1668199$

Moore, Robert L., Eric Bindler \& David Pandich. 2010. Language with attitude: American slang and Chinese lǐyŭ. Journal of Sociolinguistics 14(4). 524-538. DOI: 10.1111/j.14679841.2010.00453.x

Morgan, Marcyliena. 1993. Hip-hop hooray! The linguistic production of identity. Paper presented at the 92nd Annual Meeting of the American Anthropological Association, Washington, DC.

Nachman, Gerald. 2004. Seriously funny: The rebel comedians of the 1950s and 1960s. Back Stage Books.

Nancy A. Niedzielski \& Dennis R. Preston. 2000. Folk linguistics. De Gruyter Mouton.

Oxford English Dictionary. Available at https://www.oed.com/.

Pérez, Raúl. 2013. Learning to make racism funny in the 'color-blind' era: Stand-up comedy students, performance strategies, and the (re)production of racist jokes in public. Discourse \& Society 24(3). 478-503. DOI: 10.1177/0957926513482066

Pérez, Raúl. 2015. The hurtline and the colorline: Race and racism in American stand-up comedy from Civil Rights to color-blindness. Unpublished Ph.D. dissertation. University of California, Irvine.

Prussing-Hollowell, Andrea. 2009. Standup comedy as artistic expression: Lenny Bruce, the 1950s, and American humor. VDM Verlag Dr. Mueller,

Ross, Alison. 1998. The language of humour. Routledge.

Schwarz, Jeannine. 2010. Linguistic aspects of verbal humor in stand-up comedy. Sierke.

Seizer, Susan. 1997. Jokes, gender, and discursive distance on the Tamil popular stage. American Ethnologist 24(1). 62-90. DOI: 10.1525/ae.1997.24.1.62

Seizer, Susan. 2005. Stigmas of the Tamil stage: An ethnography of Special Drama artists in South India. Duke University Press.

Seizer, Susan. 2011. On the uses of obscenity in live stand-up comedy. Anthropological Quarterly 84(1). 209-234. DOI: 10.1353/anq.2011.0001

Smitherman, Geneva. 2006. Word from the Mother: Language and African Americans. Routledge.

Thomas, Jenny. 1995. Meaning in interaction: An introduction to pragmatics. Longman.

Tottie, Gunnel. 2002. An introduction to American English. Blackwell.

Trotta, Joe \& Oleg Blyahher. 2011. Game done changed: A look at selected AAVE features in the TV series The Wire. Moderna Språk 105(1). 15-42.

Yates, Kimberly A. 2009. When "keeping it real" goes right. In Kevin A. Wisniewski (ed.), The comedy of Dave Chappelle: Critical essays, McFarland \& Company, Inc., Publishers. 139-155.

Zoglin, Richard. 2008. Comedy at the edge: How stand-up in the 1970s changed America. Bloomsbury. 